\title{
OPEN Application of polymer-coated Macadamia integrifolia nutshell biomass impregnated with palladium for chromium(VI) remediation
}

\author{
Malvin Moyo ${ }^{1,2}$, Sekomeng Johannes Modise ${ }^{1} \&$ Vusumzi Emmanuel Pakade ${ }^{1 \bowtie}$
}

Freely suspended and porous basket restrained granules of palladium nanoparticles supported on polymer-grafted Macadamia nutshell biomass (Pd@Polym-MNS) composite were used for the treatment chromium(VI)-containing water. In the presence of formic acid, the Pd@Polym-MNS demonstrated its activity in the adsorption-reduction-based conversion of noxious chromium(VI) to less toxic chromium(III) with a low activation energy of $13.4 \mathrm{~kJ} \mathrm{~mol}^{-1}, \Delta \mathrm{H}^{0}\left(+10.8 \mathrm{~kJ} \mathrm{~mol}^{-1}\right), \Delta \mathrm{S}^{0}$ $\left(-270.0 \mathrm{~J} \mathrm{~mol}^{-1} \mathrm{~K}^{-1}\right)$, and $\Delta \mathrm{G}^{0}\left(+91.3\right.$ to $\left.+98.0 \mathrm{~kJ} \mathrm{~mol}^{-1}\right)$ indicated the exothermic, endergonic and nonspontaneous nature of the catalytic redox reaction. In addition to facilitating easy recovery, rinsing, and reuse, restraining the Pd@Polym-MNS in the basket reactor helped maintain the integrity of the catalysts by preventing violent collisions of suspended granules with the mixing apparatus and the walls of the reaction vessel. Whereas the pseudo-first-order rate constant was recorded as $0.157 \mathrm{~min}^{-1}$ upon initial use, values of the mean and relative standard deviation for the second, third and fourth consecutive uses were found to be $0.219 \mathrm{~min}^{-1}$ and $1.3 \%$, respectively. According to a response surface methodological approach to batch experimentation, the initial concentration of chromium(VI) and catalyst dosage had the greatest impact on the redox reaction rate, accounting for $85.7 \%$ and $11.6 \%$ of the variability in the value of the pseudo-first-order rate constant, respectively. Mutually beneficial effects of the combinations of high formic acid and low chromium(VI) concentration, high temperature and catalyst dosage as well as high formic acid and catalyst dosage were recorded.

From a health perspective, the presence of hexavalent chromium $[\mathrm{Cr}(\mathrm{VI})]$ in water is of primary concern owing to its cancer-causing effects on animal cells ${ }^{1}$. The toxicity of $\mathrm{Cr}(\mathrm{VI})$ is exacerbated by the ability of chromate ions, which structurally resemble sulfate ions, to be easily transported into cells through sulfate transporters ${ }^{2}$. Moreover, cell membranes are less permeable to trivalent chromium $[\mathrm{Cr}(\mathrm{III})]$ species ${ }^{3}$ rendering $\mathrm{Cr}$ (III) much less toxic than $\mathrm{Cr}(\mathrm{VI})$. Techniques based on adsorption ${ }^{4-6}$, solvent extraction ${ }^{7,8}$, and membrane filtration ${ }^{9,10}$ have proved to potentially provide feasible options for the removal of $\mathrm{Cr}(\mathrm{VI})$ from water. However, the main drawback associated with the removal techniques is that the pollutant often remains in its toxic hexavalent state, thereby retaining some degree of threat to the environment upon disposal of the used adsorbent, the retentate from membrane filtration, and the concentrate obtained after solvent recovery following solvent extraction. Several emerging strategies for the remediation of $\mathrm{Cr}(\mathrm{VI})$-contaminated water, therefore, involve the transformation of $\mathrm{Cr}(\mathrm{VI})$ to $\mathrm{Cr}(\mathrm{III})$, which, for easier containment, can be precipitated as hydroxides ${ }^{11}$. Photocatalyzed $\mathrm{Cr}(\mathrm{VI})$ reduction, which allows the use of water as the reducing agent thereby eliminating the need for chemical reductants, has sparked great interest and research effort ${ }^{12-15}$. However, the costs linked to either the generation of ultraviolet light or the development of photocatalysts with high activity in the visible light (solar) region, continue to plague the use of photocatalysis in $\mathrm{Cr}(\mathrm{VI})$ remediation.

The reduction of the $\mathrm{Cr}(\mathrm{VI})$ in, for example, aqueous hydrogen chromate $\left(\mathrm{HCrO}_{4}^{-}\right)$ions by formic acid $(\mathrm{HCOOH})$, which proceeds as per Eq. $(1)^{16,17}$, is associated with positive electrode potentials indicating thermodynamic feasibility. However, the $\mathrm{Cr}(\mathrm{VI})-\mathrm{HCOOH}$ redox reactions are still hampered by high activation

${ }^{1}$ Department of Chemistry, Vaal University of Technology, Vanderbijlpark 1911, South Africa. ${ }^{2}$ Department of Applied Chemistry, National University of Science and Technology, Bulawayo, Zimbabwe. ${ }^{\square}$ email: vusumzip@ vut.ac.za 
barriers, which necessitate the use of a catalyst ${ }^{18}$. Heterogeneous catalysis in the $\mathrm{Cr}(\mathrm{VI})$-HCOOH redox system often exploits the decarboxylation of $\mathrm{HCOOH}$, which provides adsorbed hydrogen atoms $\left(\mathrm{H}_{\mathrm{ads}}\right)$ in accordance with Eq. (2) ${ }^{19}$. The adsorbed hydrogen atoms subsequently donate their electrons to adsorbed $\mathrm{Cr}(\mathrm{VI})$ ions as exemplified by Eq. (3) ${ }^{20,21}$. Recent reports detail the catalytic activity of materials based on different precious metals in the dehydrogenation, including gold, silver, rhodium, platinum, and palladium ${ }^{22-26}$. Although the activity of less costly alternatives such as nickel ${ }^{16,20}, \operatorname{cobalt}^{27}$, and sulfur $^{28}$ has previously been reported, their use is impeded by easy leaching in the acidic $\mathrm{HCOOH}$ solution, resulting in poor reusability.

$$
\begin{aligned}
& 2 \mathrm{HCrO}_{4}{ }^{-}+3 \mathrm{HCOOH}+8 \mathrm{H}^{+} \rightarrow 2 \mathrm{Cr}^{3+}+3 \mathrm{CO}_{2}+8 \mathrm{H}_{2} \mathrm{O} \quad \mathrm{E}^{\theta}=1.48 \mathrm{~V} \\
& \mathrm{HCOOH} \rightarrow \mathrm{CO}_{2}+2 \mathrm{H}_{\mathrm{ads}} \\
& \mathrm{HCrO}_{4}{ }^{-}{ }_{\mathrm{ads}}+3 \mathrm{H}_{\mathrm{ads}}+4 \mathrm{H}^{+} \rightarrow \mathrm{Cr}^{3+}{ }_{\mathrm{ads}}+4 \mathrm{H}_{2} \mathrm{O} \\
& \mathrm{HCrO}_{4}^{-}+\mathrm{Fe}^{0}+7 \mathrm{H}^{+} \rightarrow \mathrm{Cr}^{3+}+\mathrm{Fe}^{3+}+4 \mathrm{H}_{2} \mathrm{O} \\
& \mathrm{HCrO}_{4}^{-}+3 \mathrm{Fe}^{2+}+7 \mathrm{H}^{+} \rightarrow \mathrm{Cr}^{3+}+3 \mathrm{Fe}^{3+}+4 \mathrm{H}_{2} \mathrm{O} \\
& \mathrm{HCOOH} \rightarrow \mathrm{CO}_{2}+\mathrm{H}_{2}
\end{aligned}
$$

Based on the relatively low cost of iron-based materials, several studies suggest that the use of zerovalent or divalent iron as reducing agents for the transformation of $\mathrm{Cr}(\mathrm{VI})$ to $\mathrm{Cr}$ (III) provides viable options for $\mathrm{Cr}$ (VI) remediation ${ }^{29-36}$. However, as illustrated by Eqs. (4) and (5), the resulting waste contains aqueous iron(III) species, which also precipitate alongside the Cr(III) thereby yielding large volume of sludge thus limiting the efficiency and applicability of iron-based chemical reduction techniques. Moreover, due to contamination by pure and mixed hydroxides, $\mathrm{Fe}(\mathrm{OH})_{3}$ and $\mathrm{Cr}_{\mathrm{x}} \mathrm{Fe}_{1-\mathrm{x}}(\mathrm{OH})_{3}$, the precipitated chromium(III) hydroxide has lower value than purer forms formed by precipitation from wastes devoid of iron(III) species. Since the use of $\mathrm{HCOOH}$ as the reducing only produces carbon dioxide and water, waste solutions devoid of iron(III) species can be produced. Furthermore, excess $\mathrm{HCOOH}$ in the reaction mixture can be decomposed on the surface of the catalyst to liberate hydrogen gas $\left(\mathrm{H}_{2}\right)$, an environmentally friendly fuel, in accordance with Eq. $(6)^{37,38}$, and the decomposition of excess $\mathrm{HCOOH}$ lowers the acidity of the solution prior to the precipitation of chromium(III) hydroxide. Therefore, the elevated costs associated with the precious metal-based catalysts used in the $\mathrm{Cr}(\mathrm{VI})-\mathrm{HCOOH}$ redox system can be offset by the value of the hydrogen gas and the pure chromium(III) hydroxide that can be produced via subsequent treatment with sodium hydroxide, calcium hydroxide or magnesium oxide ${ }^{39,40}$.

Even though the use of nanoparticles results in enhanced catalysis, the recovery of the nanoparticles for reuse is often difficult and poses the risk of release into the environment together with the treated water. Therefore, the catalytic nanoparticles used in the $\mathrm{HCOOH}$-mediated reduction of $\mathrm{Cr}(\mathrm{VI})$ have been immobilized on powders, granules, and films ${ }^{16,17,41-47}$. Despite several materials being used as supports for catalytic nanoparticles used in the $\mathrm{HCOOH}$-mediated reduction of $\mathrm{Cr}(\mathrm{VI})$, the use of lignocellulosic material supports is scarcely reported in the literature. Following the synthesis and characterization of palladium nanoparticles dispersed on polymer-grafted Macadamia nutshell (Pd@Polym-MNS) granules in our previous work ${ }^{48}$, we have restrained the Pd@Polym-MNS granules in a porous stainless steel basket. The practical implication of restraining the catalytic Pd@PolymMNS granules in a porous basket is that it enables easy application and recovery by immersion and retrieval, respectively, without the need for elaborate, time consuming steps in industrial wastewater treatment processes.

\section{Materials and methods}

Materials. The preparation and characterization of the composite comprising polymer-coated Macadamia integrifolia nutshell biomass with embedded Pd nanoparticles (Pd@Polym-MNS) were as described in our recent report ${ }^{48}$. Waste Macadamia nutshells were kindly donated by the Eastern Produce Estates SA (Pty) Ltd, Tzaneen, South Africa and all experiments were performed in accordance with relevant guidelines and regulations. All reagents were sourced from Johannesburg, South Africa. Potassium dichromate $\left(\mathrm{K}_{2} \mathrm{Cr}_{2} \mathrm{O}_{7}\right)$ and formic acid $(\mathrm{HCOOH}, 85 \mathrm{wt} \%)$ were purchased from Merck Chemical Company, and Rochelle Chemicals, respectively. Sodium sulfate $\left(\mathrm{Na}_{2} \mathrm{SO}_{4}\right)$, sodium chloride $(\mathrm{NaCl})$, and sodium nitrate $\left(\mathrm{NaNO}_{3}\right)$ were obtained from SigmaAldrich. Sulfuric acid $\left(\mathrm{H}_{2} \mathrm{SO}_{4}, 98 \% \mathrm{wt} \%\right)$ and hydrochloric acid $(\mathrm{HCl}), 32 \%(\mathrm{w} / \mathrm{w})$ were purchased from Associated Chemical Enterprises. A stock solution of $\mathrm{Cr}(\mathrm{VI})$ was prepared by dissolving the $\mathrm{K}_{2} \mathrm{Cr}_{2} \mathrm{O}_{7}$ in deionized water obtained from a Milli-Q water system (Milli-Q Direct, with $18.2 \mathrm{M} \Omega \mathrm{cm}$ resistivity, Merck Millipore Corporation, USA).

$\mathrm{Cr}(\mathrm{VI})$ conversion experiments. The experiments to assess the conversion of $\mathrm{Cr}(\mathrm{VI})$ by reaction with $\mathrm{HCOOH}$ were carried out in three batches. In the first batch of experiments, mixed $\mathrm{Cr}(\mathrm{VI})-\mathrm{HCOOH}$ solutions were prepared by diluting mixtures of the $\mathrm{Cr}(\mathrm{VI})$ stock solution, $\mathrm{H}_{2} \mathrm{SO}_{4}$ and $\mathrm{HCOOH}$ with deionized water. Thereafter, the solution was incubated at a specific temperature, the Pd@Polym-MNS was added, and the suspension was magnetically stirred throughout the experiment. A porous basket reactor comprising a 40 mesh stainless steel cylindrical basket into which Pd@Polym-MNS was weighed before covering with a shafted lid was used in the second and third experimental batches. In the second batch of $\mathrm{Cr}(\mathrm{VI})$ conversion experiments, the Pd@Polym-MNS-loaded basket was immersed in an incubated mixed $\mathrm{Cr}(\mathrm{VI})$-HCOOH solution prepared by the dilution of mixtures of the $\mathrm{Cr}(\mathrm{VI})$ stock solution, $\mathrm{HCOOH}, \mathrm{H}_{2} \mathrm{SO}_{4}, \mathrm{NaCl}$, and $\mathrm{NaNO}_{3}$ with tap water. 


\begin{tabular}{|l|l|l|l|l|l|l|}
\hline & & \multicolumn{5}{|c|}{ Variable levels and values } \\
\cline { 5 - 9 } Input variables & Code & $-\mathbf{2}$ & $\mathbf{- 1}$ & $\mathbf{0}$ & $\mathbf{+ 1}$ & $\mathbf{+ 2}$ \\
\hline Initial $\mathrm{Cr}(\mathrm{VI})$ concentration, $[\mathrm{Cr}(\mathrm{VI})]_{0},(\mathrm{mM})$ & $X_{1}$ & 0.5 & 1.5 & 2.0 & 2.5 & 3.0 \\
\hline Initial $\mathrm{HCOOH}$ concentration, $[\mathrm{HCOOH}]_{0},(\mathrm{mM})$ & $X_{2}$ & 50 & 100 & 200 & 300 & 500 \\
\hline Pd@Polym-MNS dose, Dose, $\left(\mathrm{g} \mathrm{L}^{-1}\right)$ & $X_{3}$ & 0.5 & 1.0 & 2.0 & 3.0 & 5.0 \\
\hline Temperature, $T,\left({ }^{\circ} \mathrm{C}\right)$ & $X_{4}$ & 15 & 25 & 35 & 45 & 55 \\
\hline
\end{tabular}

Table 1. Input variable codes, levels, and values of the central composite design-based experiment.

The basket was either kept stationary as the solution was stirred using an overhead paddle or the solution was stirred by rotation of the basket reactor on a dissolution testing apparatus (Vision G2 Classic 6, Teledyne Hanson Research, Chatsworth, CA, USA). In order to facilitate the analysis of the combined influence of initial Cr(VI) concentration $\left(X_{1}\right)$, initial HCOOH concentration $\left(X_{2}\right)$, Pd@Polym-MNS dose $\left(X_{3}\right)$, and temperature $\left(X_{4}\right)$ on the rate of $\mathrm{Cr}(\mathrm{VI})$ conversion, the third batch of $\mathrm{Cr}(\mathrm{VI})$ conversion experiments was conducted as per a $2^{4}$ factorial central composite experimental design with the coded factor levels and values of the input or independent variables presented in Table 1 .

Using the rate constant of the model providing the best fit to the $\mathrm{Cr}(\mathrm{VI})$ conversion kinetics as the response or dependent variable $(Y)$, the relationship between the response and input variables was modeled using a quadratic equation expressed as:

$$
\begin{aligned}
\mathrm{Y}= & \beta_{0}+\beta_{1} \mathrm{X}_{1}+\beta_{2} \mathrm{X}_{2}+\beta_{3} \mathrm{X}_{3}+\beta_{4} \mathrm{X}_{4}+\beta_{12} \mathrm{X}_{1} \mathrm{X}_{2}+\beta_{13} \mathrm{X}_{1} \mathrm{X}_{3}+\beta_{14} \mathrm{X}_{1} \mathrm{X}_{4} \\
& +\beta_{23} \mathrm{X}_{2} \mathrm{X}_{3}+\beta_{24} \mathrm{X}_{2} \mathrm{X}_{4}+\beta_{34} \mathrm{X}_{3} \mathrm{X}_{4}+\beta_{11} \mathrm{X}_{1}{ }^{2}+\beta_{22} \mathrm{X}_{2}{ }^{2}+\beta_{33} \mathrm{X}_{3}{ }^{2}+\beta_{44} \mathrm{X}_{4}{ }^{2}
\end{aligned}
$$

where $Y$ represents the predicted response; $\beta_{0}$ the offset term; $\beta_{1}, \beta_{2}, \beta_{3}$, and $\beta_{4}$ the linear coefficients; $\beta_{12}, \beta_{13}$, $\beta_{14}, \beta_{23}, \beta_{24}$ and $\beta_{34}$ the interaction coefficients; and $\beta_{11}, \beta_{22}, \beta_{33}$, and $\beta_{44}$ the quadratic coefficients. $X_{1}, X_{2}, X_{3,}$ and $X_{4}$ represent the input variables as defined in Table $1^{49}$. Using Statistica software (Version 10.0, StatSoft, Inc., Tulusa, OK, USA), Eq. (7) was fitted to the experimental data, and surface plots were created to evaluate the combined effects of the input variables.

At specific times during the course of each $\mathrm{Cr}(\mathrm{VI})$ conversion experiment, a $3.5 \mathrm{~mL}$ sample of the working solution was transferred into an optical quartz cell with a $1 \mathrm{~cm}$ path length and its ultraviolet-visible (UV-Vis) spectral absorption was recorded on a UV-Vis spectrophotometer (Cary 60, Agilent Technologies, Santa Clara, CA, USA) over a wavelength range of $300 \mathrm{~nm}$ to $500 \mathrm{~nm}$ at a scanning rate of $1200 \mathrm{~nm} \mathrm{~min}{ }^{-1}$ with increments of $2 \mathrm{~nm}$ and a step time of $0.10 \mathrm{~s}$. Immediately afterward (approximately $2 \mathrm{~min}$ after sampling), the sample was returned to the reaction mixture. The evolution of $\mathrm{Cr}(\mathrm{VI})$ concentration was monitored by measurement of the absorbance of the peaks at the characteristic wavelengths between 350 and $375 \mathrm{~nm}^{50}$. In accordance with the Beer-Lambert Law, which states that spectral absorbance is directly proportional to concentration, the absorbance of the $\mathrm{Cr}(\mathrm{VI})$ solutions at the beginning of each $\mathrm{Cr}(\mathrm{VI})$ conversion experiment and at any time $t$ thereafter, denoted $A_{0}$ and $A_{t}$ (arbitrary units), respectively, was related to the $\mathrm{Cr}(\mathrm{VI})$ concentration at the beginning of each experiment and at any time $t$ during the experiment, denoted where $[\mathrm{Cr}(\mathrm{VI})]_{0}$ and $[\mathrm{Cr}(\mathrm{VI})]_{t}\left(\mathrm{mmol} \mathrm{L}^{-1}\right)$, respectively, in accordance with Eq. (8). The fraction of $\mathrm{Cr}(\mathrm{VI})$ that remained in the solution any time during the experiment, designated Residual Cr(VI) (\%), was calculated using Eq. (9).

$$
\frac{\mathrm{A}_{\mathrm{t}}}{\mathrm{A}_{0}}=\frac{[\mathrm{Cr}(\mathrm{VI})]_{\mathrm{t}}}{[\mathrm{Cr}(\mathrm{VI})]_{0}}
$$

$$
\text { Residual } \operatorname{Cr}(\mathrm{VI})=\frac{\mathrm{A}_{\mathrm{t}}}{\mathrm{A}_{0}} \times 100 \%
$$

The possibility of palladium leaching during the treatment of the acidic mixed $\mathrm{Cr}(\mathrm{VI})-\mathrm{HCOOH}$ solutions was evaluated by analysis of final solutions using an inductively coupled plasma optical emission spectrophotometer (iCAP 7000, Thermo Fisher Scientific, Waltham, MA, USA).

Kinetic and thermodynamic data analysis. The rate law for $\mathrm{Cr}(\mathrm{VI})$ conversion by reaction with $\mathrm{HCOOH}$ is represented by Eq. (10) where $v\left(\mathrm{mmol} \mathrm{L}^{-1} \mathrm{~min}^{-1}\right)$ is the rate to $\mathrm{Cr}(\mathrm{VI})$ conversion, $[\mathrm{Cr}(\mathrm{VI})](\mathrm{mmol}$ $\left.\mathrm{L}^{-1}\right)$ and $[\mathrm{HCOOH}]\left(\mathrm{mmol} \mathrm{L}^{-1}\right)$ are the concentrations of $\mathrm{Cr}(\mathrm{VI})$ and $\mathrm{HCOOH}$, respectively, $k\left(\mathrm{mmol}^{(1-a-b)} \mathrm{L}^{(a}\right.$ $\left.+b-1) \mathrm{min}^{-1}\right)$ is the rate constant, and $a$ (dimensionless) and $b$ (dimensionless) represent the order of reaction with respect to $\mathrm{Cr}(\mathrm{VI})$ and $\mathrm{HCOOH}$, respectively. Since an excess amount of $\mathrm{HCOOH}$ was used throughout the $\mathrm{Cr}(\mathrm{VI})$ conversion experiments, changes in $[\mathrm{HCOOH}]$ can be considered insignificant so that $k[\mathrm{HCOOH}]^{a}$ constitutes a new rate constant referred to as the apparent rate constant, $k_{a p p}\left(\operatorname{mmol}^{(1-b)} \mathrm{L}^{(b-1)} \min ^{-1}\right)$, and the rate law for $\mathrm{Cr}(\mathrm{VI})$ conversion by reaction with $\mathrm{HCOOH}$ can be expressed as Eq. (11).

$$
\mathrm{v}=\frac{\mathrm{d}[\mathrm{Cr}(\mathrm{VI})]}{\mathrm{dt}}=-\mathrm{k}[\mathrm{HCOOH}]^{\mathrm{a}}[\mathrm{Cr}(\mathrm{VI})]^{\mathrm{b}}
$$




$$
\mathrm{v}=\frac{\mathrm{d}[\mathrm{Cr}(\mathrm{VI})]}{\mathrm{dt}}=-\mathrm{k}_{\mathrm{app}}[\mathrm{Cr}(\mathrm{VI})]^{\mathrm{b}}
$$

The kinetics of $\mathrm{Cr}(\mathrm{VI})$ conversion were profiled using the pseudo-zeroth-order, pseudo-first-order and pseudo-second-order models associated with the integrated rate laws expressed as Eqs. (12), (13) and (14) where the orders of reaction with respect to $\mathrm{Cr}(\mathrm{VI})$ are $b=0, b=1$ and $b=2$ in addition to $k_{0, a p p}\left(\mathrm{mmol} \mathrm{L}^{-1} \mathrm{~min}^{-1}\right), k_{1, a p p}$ $\left(\mathrm{min}^{-1}\right)$ and $k_{2, a p p}\left(\mathrm{mmol}^{-1} \mathrm{~L} \mathrm{~min}^{-1}\right)$ representing the apparent pseudo-first-order rate constant, respectively.

$$
\begin{array}{cl}
\text { Pseudo }- \text { zeroth }- \text { order }: & \frac{[\mathrm{Cr}(\mathrm{VI})]_{\mathrm{t}}}{[\mathrm{Cr}(\mathrm{VI})]_{0}}=1-\frac{\mathrm{k}_{0, \mathrm{app}} \mathrm{t}}{[\mathrm{Cr}(\mathrm{VI})]_{0}} \\
\text { Pseudo }- \text { first }- \text { order }: & \frac{[\mathrm{Cr}(\mathrm{VI})]_{\mathrm{t}}}{[\mathrm{Cr}(\mathrm{VI})]_{0}}=\exp \left(-\mathrm{k}_{1, \mathrm{app}} \mathrm{t}\right) \\
\text { Pseudo }- \text { second }- \text { order }: & \frac{[\mathrm{Cr}(\mathrm{VI})]_{\mathrm{t}}}{[\mathrm{Cr}(\mathrm{VI})]_{0}}=\frac{1}{[\mathrm{Cr}(\mathrm{VI})]_{0} \mathrm{k}_{2, \mathrm{app}} \mathrm{t}+1}
\end{array}
$$

The thermodynamic data were analyzed by plotting the first-order rate constant versus temperature and carrying out nonlinear regression fitting of the Arrhenius and Eyring equations expressed as Eq. (15) and Eq. (16), respectively, where $k_{a p p}\left(\mathrm{mmol}^{(1-b)} \mathrm{L}^{(b-1)} \mathrm{min}^{-1}\right)$ is the rate constant, $A\left(\mathrm{mmol}^{(1-b)} \mathrm{L}^{(b-1)} \mathrm{min}^{-1}\right)$ is the preexponential factor, $E_{a}\left(\mathrm{~J} \mathrm{~mol}^{-1}\right)$ is the apparent activation energy of the reaction, $R$ is the universal gas constant $\left(8.3145 \mathrm{~J} \mathrm{~K}^{-1} \mathrm{~mol}^{-1}\right), T(\mathrm{~K})$ is the temperature, $E_{y}$ is an Eyring equation constant $\left(1 \mathrm{mmol}^{(1-b)} \mathrm{L}^{(b-1)} \mathrm{min}^{-1}\right.$ where $b$, the order of reaction with respect to $\mathrm{Cr}(\mathrm{VI})$ is 0,1 or 2$), k_{B}$ is Boltzmann's constant $\left(1.3807 \times 10^{-23} \mathrm{~J} \mathrm{~K}^{-1}\right), h$ is Planck's constant $\left(6.6262 \times 10^{-34} \mathrm{~J} \mathrm{~s}\right), \Delta S^{\ddagger}\left(\mathrm{J} \mathrm{mol}^{-1} \mathrm{~K}^{-1}\right)$ is the change in entropy of activation and $\Delta H^{\ddagger}\left(\mathrm{J} \mathrm{mol}^{-1}\right)$ is the change in enthalpy of activation ${ }^{51,52}$. Values of the change in Gibbs free energy of activation, $\Delta G^{\neq}\left(\mathrm{J} \mathrm{mol}^{-1}\right)$, at each temperature were further calculated as expressed in Eq. (17).

$$
\begin{gathered}
\text { Arrhenius : } \quad \mathrm{k}_{\mathrm{app}}=\mathrm{A} \exp \left(-\frac{\mathrm{E}_{\mathrm{a}}}{\mathrm{RT}}\right) \\
\text { Eyring: } \quad \mathrm{k}_{\mathrm{app}}=\mathrm{E}_{\mathrm{y}} \frac{\mathrm{k}_{\mathrm{B}} \mathrm{T}}{\mathrm{h}} \exp \left(\frac{\Delta S^{\ddagger}}{\mathrm{R}}-\frac{\Delta \mathrm{S}^{\ddagger}}{\mathrm{RT}}\right) \\
\Delta \mathrm{G}^{\ddagger}=\Delta \mathrm{H}^{\ddagger}-\mathrm{T} \Delta \mathrm{S}^{\ddagger}
\end{gathered}
$$

Using nonlinear regression based on minimization of the Chi-square statistic, denoted $\chi^{2}$ (dimensionless), curves relating $[\mathrm{Cr}(\mathrm{VI})]_{t} /[\mathrm{Cr}(\mathrm{VI})]_{0}$ to $t$, and $k_{\text {app }}$ to $T$, were fitted to the kinetic and thermodynamic experimental data, respectively. The corresponding values of the coefficient of determination, $R^{2}$ (dimensionless), were also calculated. The values of $\chi^{2}$ and $R^{2}$ were determined using Eqs. (18) and (19), respectively, expressed as:

$$
\begin{gathered}
\chi^{2}=\sum_{i=1}^{n} \frac{\left(x_{i, \text { expt }}-x_{i, \bmod }\right)^{2}}{x_{i, \bmod }} \\
\mathrm{R}^{2}=1-\frac{\sum_{\mathrm{i}=1}^{\mathrm{n}}\left(\mathrm{x}_{\mathrm{i} \text { expt }}-\mathrm{x}_{\mathrm{i}, \mathrm{mod}}\right)^{2}}{\sum_{\mathrm{i}=1}^{\mathrm{n}}\left(\mathrm{x}_{\mathrm{i} \text { expt }}-\overline{\mathrm{x}}_{\mathrm{i}, \text { expt }}\right)^{2}}
\end{gathered}
$$

where $x_{i, \text { expt }}$ represents the measured or experimentally determined values of $[C r(V I)]_{t} /[C r(V I)]_{0}$ or $k_{a p p}, x_{i, \text { mod }}$ the model-predicted values of $[\mathrm{Cr}(V I)]_{t} /[\mathrm{Cr}(V I)]_{0}$ or $k_{a p p}, \overline{\mathrm{x}}_{\mathrm{i} \text {,expt }}$ the average of the experimentally determined $[\mathrm{Cr}(V I)]_{t} /[\mathrm{Cr}(V I)]_{0}$ or $k_{a p p}$ measurements, and $n$ is the number of measurements ${ }^{53}$. Using the Solver Add-in of Microsoft Excel software, the curve fitting process involved a trial-and-error-based iterative method wherein the parameters of each model equation were adjusted until the lowest value of $\chi^{2}$ was attained.

\section{Results and discussion}

Efficacy of the $\mathrm{HCOOH}-\mathrm{Cr}(\mathrm{VI})$ redox system in $\mathrm{Cr}(\mathrm{VI})$ conversion. In order to emphasize the efficacy of the reducing agency of $\mathrm{HCOOH}$ in the Pd@Polym-MNS facilitated conversion of $\mathrm{Cr}(\mathrm{VI})$ to $\mathrm{Cr}$ (III) ions, two varieties of $\mathrm{Cr}(\mathrm{VI})$ solution were treated with the Pd@Polym-MNS. The first variety of solution contained $0.6 \mathrm{mM} \mathrm{Cr}(\mathrm{VI}), 1875 \mathrm{mM} \mathrm{H}_{2} \mathrm{SO}_{4}$ and $1000 \mathrm{mM} \mathrm{HCOOH}$ whereas the second contained only $\mathrm{Cr}(\mathrm{VI})(0.6 \mathrm{mM})$ and $\mathrm{H}_{2} \mathrm{SO}_{4}(1875 \mathrm{mM})$. On both occasions, function of the sulfate ions supplied by the $\mathrm{H}_{2} \mathrm{SO}_{4}$ was to mask the protonated and polar functional groups on the Pd@Polym-MNS surfaces thereby hindering the adsorption of $\mathrm{Cr}(\mathrm{VI})$ ions. Having masked the protonated and polar functional groups, the principal mechanisms responsible observed decreases in $\mathrm{Cr}(\mathrm{VI})$ concentration were redox reaction involving $\mathrm{Cr}(\mathrm{VI})$ ions adsorbed on the exposed surfaces of the Pd particles dispersed on the Pd@Polym-MNS. As shown in Fig. 1, the spectra of the two solutions obtained at different times during the respective experiments exhibited intense peaks near $350 \mathrm{~nm}$ assigned to oxygen-to- $\mathrm{Cr}(\mathrm{VI})$ charge transfer transition in $\mathrm{Cr}(\mathrm{VI})$ ions $^{54}$. 

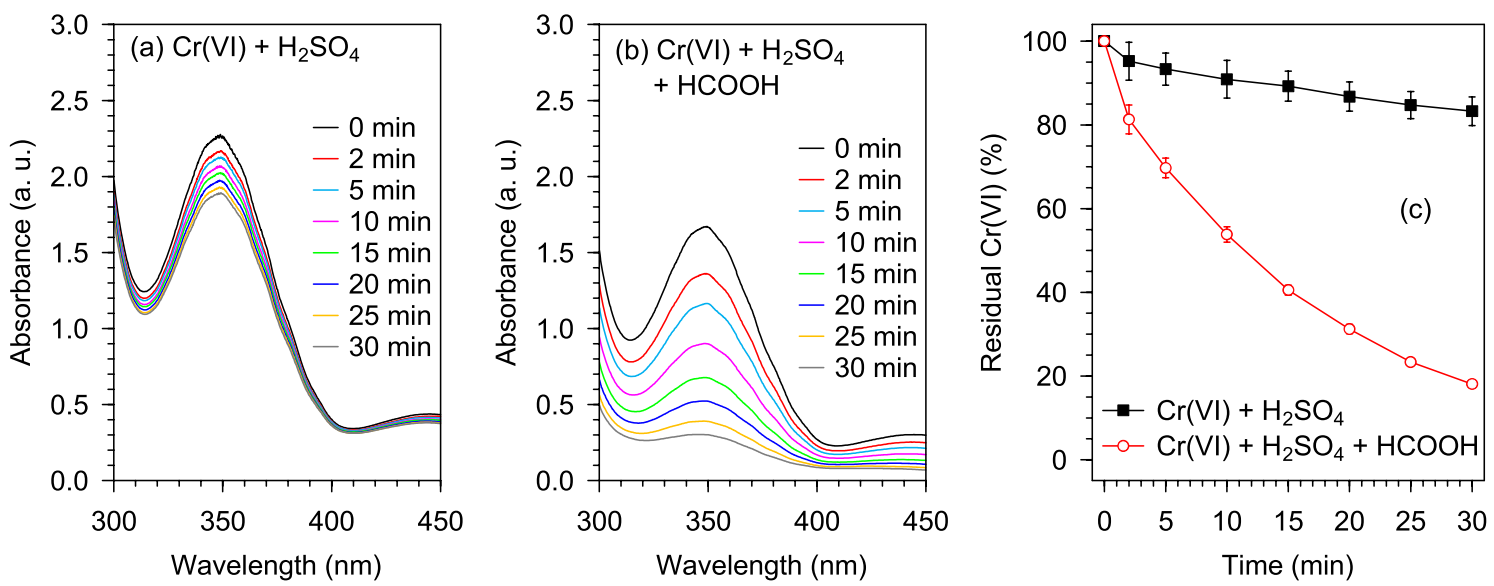

Figure 1. Evolution of the UV-Vis spectra of Pd@Polym-MNS-treated Cr(VI) aqueous solution with added (a) $\mathrm{H}_{2} \mathrm{SO}_{4}$ only (control), and (b) $\mathrm{H}_{2} \mathrm{SO}_{4}$ and $\mathrm{HCOOH}$. (c) Corresponding evolution of residual $\mathrm{Cr}(\mathrm{VI})$ in solution. Fixed experimental conditions: V=250 mL; Pd@Polym-MNS dose $=2.0 \mathrm{~g} \mathrm{~L}^{-1}$; $[\mathrm{Cr}(\mathrm{VI})]_{0}=2.0 \mathrm{mM}$; $\left[\mathrm{H}_{2} \mathrm{SO}_{4}\right]_{0}=1875 \mathrm{mM} ;[\mathrm{HCOOH}]_{0}=1000 \mathrm{mM} ; \mathrm{T}=25^{\circ} \mathrm{C}$.<smiles>O=COCC(=O)O</smiles>

\section{1. $\mathrm{HCOOH} \& \mathrm{Cr}(\mathrm{VI})$ adsorption}

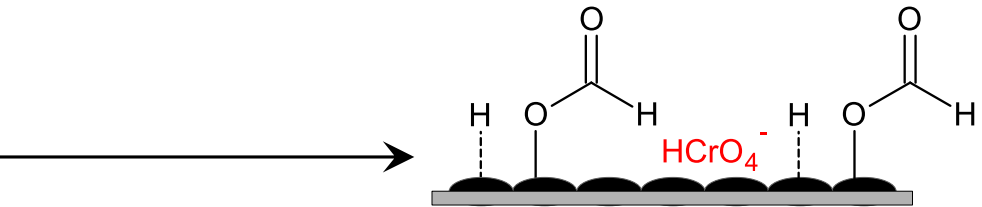

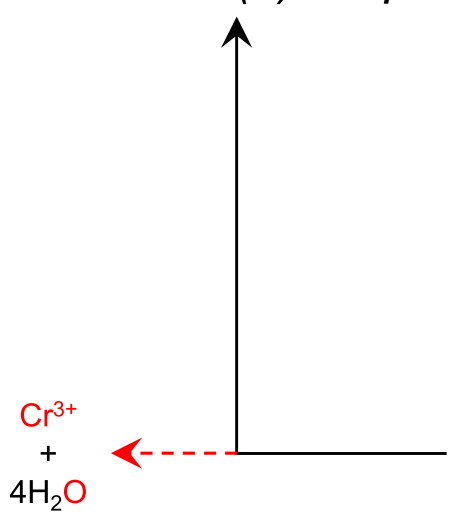

2. $\mathrm{HCOOH}$ Decarboxylation

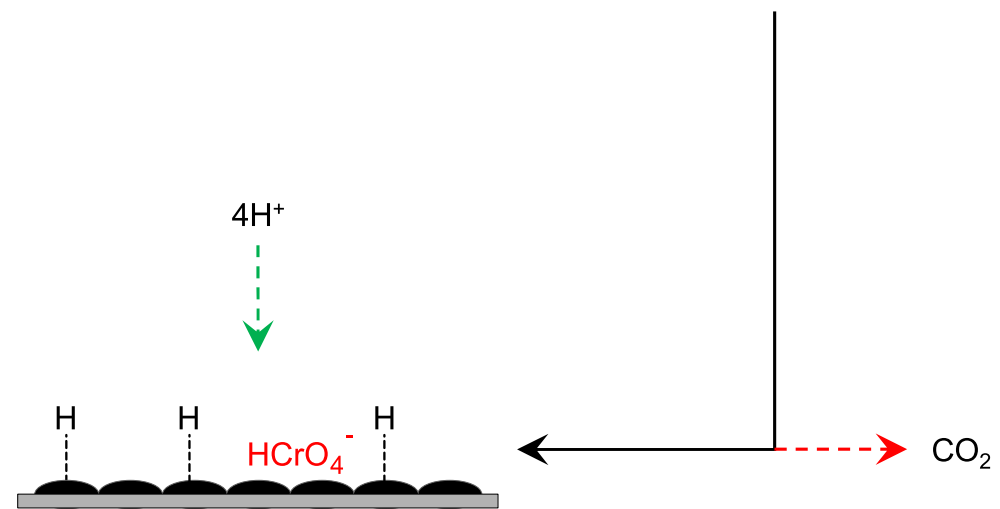

3. $\mathrm{Cr}(\mathrm{VI})-\mathrm{H}$ atom redox reaction

$$
\mathrm{HCrO}_{4}^{-} \text {ads }+3 \mathrm{H}_{\mathrm{ads}}+4 \mathrm{H}^{+} \rightarrow \mathrm{Cr}^{3+} \text { ads }+4 \mathrm{H}_{2} \mathrm{O}
$$

Figure 2. Tentative mechanism for Cr(VI) reduction by HCOOH over Pd@Polym-MNS.

Whether or not HCOOH was included in the Pd@Polym-MNS-treated solution, there was a gradual decrease in the characteristic peak attesting to the occurrence of $\mathrm{Cr}(\mathrm{VI})$ reduction on the Pd@Polym-MNS surfaces. However, the extent of $\mathrm{Cr}(\mathrm{VI})$ reduction appeared to be much greater in the solution that contained $\mathrm{HCOOH}$, which, after 30 min of contact with the Pd@Polym-MNS, had a residual Cr(VI) proportion of $18.1 \%$ in comparison to 83.3\% noted for the solution that did not contain $\mathrm{HCOOH}$ (Fig. 1c). The less effective reduction of $\mathrm{Cr}(\mathrm{VI})$ in the absence of $\mathrm{HCOOH}$ was ascribed to less potent reducing agency of oxidizable organic functional groups of the Pd@Polym-MNS, chiefly primary amines $\left(-\mathrm{NH}_{2}\right)$ and hydroxyls $\left(-\mathrm{CH}_{2} \mathrm{OH}\right)$, which were oxidized upon redox 

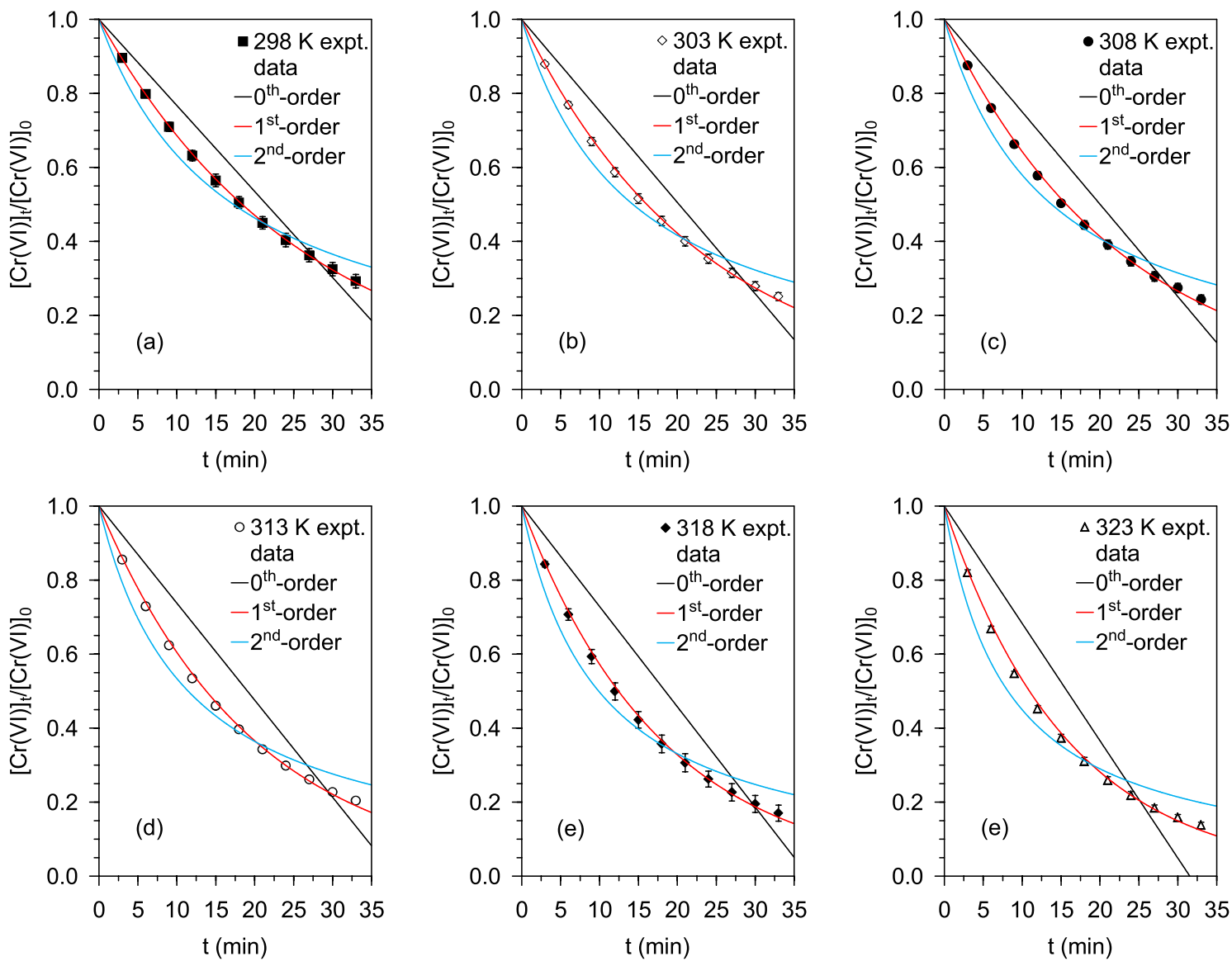

Figure 3. Kinetic plots of remaining fraction of $\mathrm{Cr}(\mathrm{VI})$ versus reaction time for $\mathrm{Cr}(\mathrm{VI})$ reduction by HCOOH over Pd@Polym-MNS at different temperatures: (a) $298 \mathrm{~K}$, (b) $303 \mathrm{~K}$, (c) $308 \mathrm{~K}$, (d) $313 \mathrm{~K}, 318 \mathrm{~K}$ and $323 \mathrm{~K}$. Fixed experimental conditions: V=100 mL; Pd@Polym-MNS dose $=2.0 \mathrm{~g} \mathrm{~L}^{-1}$; $[\mathrm{Cr}(\mathrm{VI})]_{0}=0.6 \mathrm{mM}$; $[\mathrm{HCOOH}]_{0}=75 \mathrm{mM}$.

\begin{tabular}{|l|l|l|l|l|l|l|l|l|l|}
\hline \multirow{2}{*}{$\mathrm{T}(\mathbf{K})$} & \multicolumn{4}{|l|}{ Pseudo-zeroth-order } & \multicolumn{3}{l|}{ Pseudo-first-order } & \multicolumn{3}{l|}{ Pseudo-second-order } \\
\cline { 2 - 11 } & $\boldsymbol{k}_{\boldsymbol{0}}$ & $\chi^{\mathbf{2}}$ & $\boldsymbol{R}^{\mathbf{2}}$ & $\boldsymbol{k}_{\boldsymbol{l}}$ & $\chi^{\mathbf{2}}$ & $\boldsymbol{R}^{\mathbf{2}}$ & $\boldsymbol{k}_{\mathbf{2}}$ & $\chi^{\mathbf{2}}$ & $\boldsymbol{R}^{\mathbf{2}}$ \\
\hline 298 & 0.0139 & 0.0743 & 0.8942 & 0.0377 & 0.0002 & 0.9998 & 0.0964 & 0.0303 & 0.9600 \\
\hline 303 & 0.0148 & 0.1298 & 0.8348 & 0.0431 & 0.0010 & 0.9991 & 0.1165 & 0.0384 & 0.9562 \\
\hline 308 & 0.0150 & 0.1448 & 0.8168 & 0.0441 & 0.0015 & 0.9986 & 0.1208 & 0.0386 & 0.9567 \\
\hline 313 & 0.0157 & 0.2261 & 0.7485 & 0.0503 & 0.0024 & 0.9982 & 0.1455 & 0.0531 & 0.9510 \\
\hline 318 & 0.0163 & 0.3075 & 0.7043 & 0.0557 & 0.0024 & 0.9985 & 0.1686 & 0.0718 & 0.9456 \\
\hline 323 & 0.0190 & 1.2055 & 0.7312 & 0.0634 & 0.0046 & 0.9979 & 0.2039 & 0.0922 & 0.9458 \\
\hline
\end{tabular}

Table 2. Fitted pseudo-first-order, pseudo-first-order, pseudo-second-order rate constant and error statistic values for the $\mathrm{HCOOH}$-mediated $\mathrm{Cr}(\mathrm{VI})$ conversion on Pd@Polym-MNS at different temperatures.

reaction with the $\mathrm{Cr}(\mathrm{VI})$ ions ${ }^{48}$. In addition to having lower potency in comparison to that of $\mathrm{HCOOH}$, the oxidizable organic functional groups were present in lower concentrations than the HCOOH. On account of the $\mathrm{Cr}(\mathrm{VI})$ ions undergoing redox reaction with adsorbed hydrogen atoms from the degradation of $\mathrm{HCOOH}$ on the Pd@Polym-MNS surface as illustrated in Fig. 2 followed by the desorption of the nascent Cr(III) ions, which regenerated the $\mathrm{Cr}(\mathrm{VI})$ adsorption sites for further uptake of $\mathrm{Cr}(\mathrm{VI})$ ions ${ }^{17}$, the extent $\mathrm{Cr}(\mathrm{VI})$ adsorption from the solution containing $\mathrm{HCOOH}$ was higher. Consequently, the rate at which the intensity of the characteristic peak decreased was higher when the $\mathrm{HCOOH}$-containing solution was treated with the Pd@Polym-MNS.

Thermodynamics of Pd@Polym-MNS-facilitated $\mathrm{Cr}(\mathrm{VI})$ conversion. The thermodynamic aspects of the catalytic $\mathrm{Cr}(\mathrm{VI})$ conversion reaction were assessed by treatment of aliquots of a mixed $\mathrm{Cr}(\mathrm{VI})-\mathrm{HCOOH}$ solution containing $0.6 \mathrm{mM} \mathrm{Cr}(\mathrm{VI})$ and $75 \mathrm{mM}$ HCOOH with Pd@Polym-MNS incubated at different temperatures. The corresponding kinetic plots of $[\mathrm{Cr}(\mathrm{VI})]_{t} /[\mathrm{Cr}(\mathrm{VI})]_{0}$ versus $t$ with fitted equations of the pseudo-zeroth- 


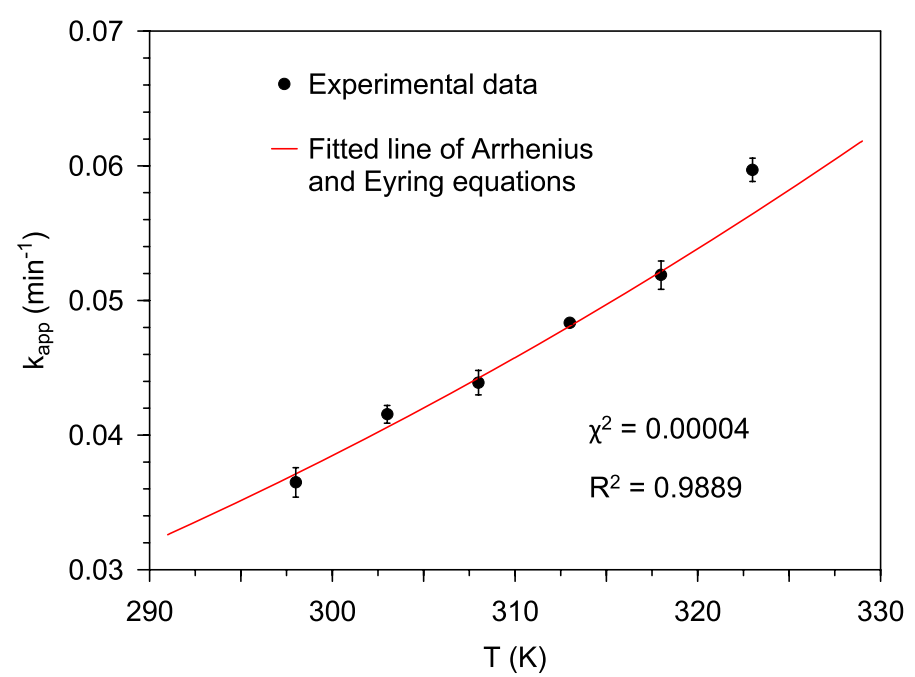

Figure 4. Effect of temperature if the apparent rate constant for $\mathrm{Cr}(\mathrm{VI})$ reduction by HCOOH over Pd@PolymMNS.

\begin{tabular}{|c|c|c|c|}
\hline Material & Pd loading (wt \%) & $\mathrm{E}_{\mathrm{a}}\left(\mathrm{kJ} \mathrm{\textrm {mol } ^ { - 1 } )}\right.$ & References \\
\hline Polyethersulfone bead-immobilized Pd nanoparticles & 0.4 & 40.25 & 17 \\
\hline Viral-templated Pd nanocatalysts & - & 27.3 & 57 \\
\hline Functionalized silica-supported Pd nanoparticles & 1.4 & 25.9 & 58 \\
\hline Graphene oxide-supported Pd nanoparticles & 1.2 & 24.5 & 59 \\
\hline Macadamia nutshell-supported Pd nanoparticles & 13.25 & 13.4 & This work \\
\hline
\end{tabular}

Table 3. Activation energies of $\mathrm{HCOOH}$-assisted $\mathrm{Cr}(\mathrm{VI})$ conversion on different Pd-loaded materials.

order, pseudo-first-order, and pseudo-second-order kinetic models are displayed in Fig. 3. As shown by the $\mathrm{Cr}(\mathrm{VI})]_{t} /[\mathrm{Cr}(\mathrm{VI})]_{0}$ versus $t$ plots, and in accordance with production of the lowest values of $\chi^{2}$ plus the highest $R^{2}$ values in the 0.9986 to 0.9999 range (Table 2), the kinetic data were well simulated by the pseudo-first-order kinetic model, which matched previous reports ${ }^{17,43,48,55,56}$. Therefore, the rate constant of the pseudo-first-order model equation was used as the apparent rate constant $\left(k_{\text {app }}\right)$ for evaluation of the thermodynamics of the $\mathrm{Cr}(\mathrm{VI})$ conversion process.

Figure 4 shows the relationship between temperature and the apparent rate constant. An increase in temperature resulted in an increase in the value of the rate constant suggesting that the $\mathrm{Cr}(\mathrm{VI})$ conversion process was endothermic. Application of the exponential functions that represent the Arrhenius and Eyring equations to the thermodynamic data yielded good fit to the plot of the apparent rate constant versus temperature with a coefficient of determination $\left(R^{2}\right)$ value of 0.9889 . From the parameters of the Arrhenius equation, the activation energy was found to be $13.4 \mathrm{~kJ} \mathrm{~mol}^{-1}$, which, suggested that the rate-controlling step of the overall $\mathrm{Cr}(\mathrm{VI})$ conversion process was physical in nature ${ }^{6}$. Therefore, the rate of mass transfer (diffusion), as opposed to the $\mathrm{Cr}(\mathrm{VI})-\mathrm{HCOOH}$ redox reaction in the adsorbed phase, was the rate-controlling step.

Table 3 shows how the activation energy recorded in this work compared to that of other HCOOH-mediated $\mathrm{Cr}(\mathrm{VI})$ conversion processes on different Pd-loaded materials. There appeared to be a negative correlation between Pd loading and activation energy where the activation energy was lower for materials with higher Pd loading. Therefore, the low activation energy associated with the Pd@Polym-MNS was attributed to high Pd nanoparticle loading, which resulted in extensive surface coverage by the coated Pd. In turn, high Pd nanoparticle loading rendered the rate of the $\mathrm{Cr}(\mathrm{VI})$ conversion process so fast that the surface reaction step was not responsible for rate control.

Application of the Eyring equation yielded the values of change in enthalpy, entropy, and Gibbs free energy of activation given in Table 4 . The positive change in enthalpy of activation $\left(\Delta H^{\ddagger}\right)$ confirmed that the $\operatorname{Cr}(\mathrm{VI})$ conversion process was endothermic. The low value of $\Delta H^{*}$ promoted the formation of the transition-state complex and was attributed to the catalytic action of the Pd coating of the Pd@Polym-MNS. The negative change in entropy of activation $\left(\Delta S^{\ddagger}\right)$ suggested that there was an improvement in the order of the reacting system, signifying the formation of a transition-state complex with fewer vibrational, rotational, and transitional states than the $\mathrm{HCrO}_{4}{ }^{-}$and $\mathrm{HCOOH}$ species in the ground state ${ }^{60}$. In turn, this confirmed that the reaction that occurred on the surfaces of the Pd@Polym-MNS involved an associative mechanism in which the $\mathrm{Cr}(\mathrm{VI})$ and $\mathrm{HCOOH}$ species were adsorbed on the Pd@Polym-MNS surface ${ }^{61,62}$. 


\begin{tabular}{|l|l|l|l|}
\hline $\mathbf{T}(\mathbf{K})$ & $\boldsymbol{\Delta} \mathbf{G}^{\ddagger}\left(\mathbf{k J ~} \mathbf{~ m o l}^{-\mathbf{1}}\right)$ & $\Delta \boldsymbol{H}^{\ddagger}\left(\mathbf{k J ~} \mathbf{~ m o l}^{\mathbf{- 1}}\right)$ & $\Delta \boldsymbol{S}^{\ddagger}\left(\mathbf{J ~ m o l}^{\mathbf{- 1}} \mathbf{K}^{\mathbf{- 1}}\right)$ \\
\hline 298 & 91.3 & 10.8 & -270.0 \\
\hline 303 & 92.6 & & \\
\hline 308 & 94.0 & & \\
\hline 313 & 95.3 & & \\
\hline 318 & 96.7 & & \\
\hline 323 & 98.0 & & \\
\hline
\end{tabular}

Table 4. Change in enthalpy, entropy, and Gibbs free energy of activation for $\mathrm{HCOOH}-$ mediated $\mathrm{Cr}(\mathrm{VI})$ conversion on Pd@Polym-MNS.

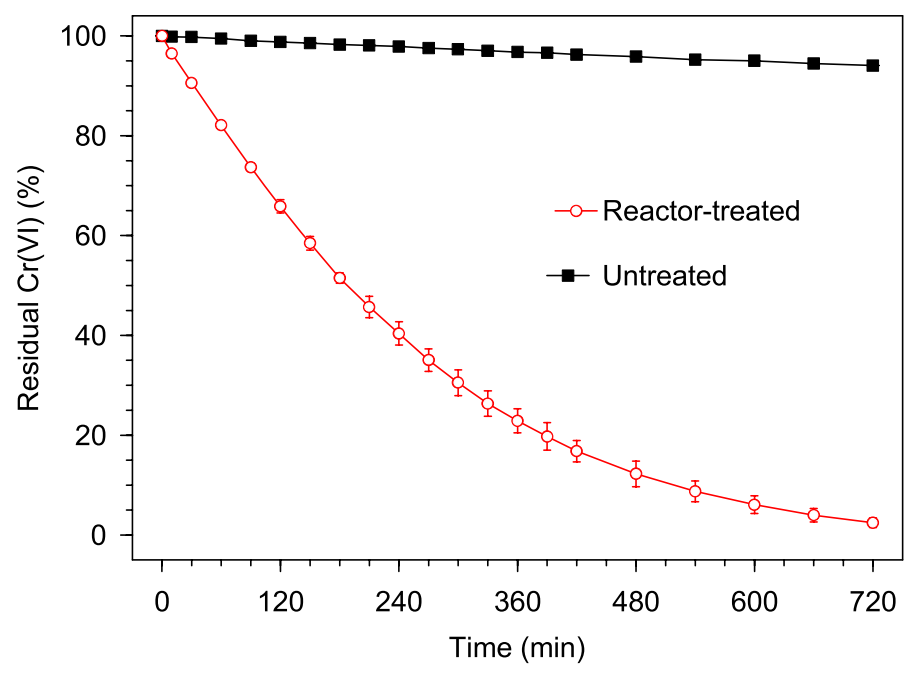

Figure 5. Evolution of the residual Cr(VI) in a mixed $\mathrm{Cr}(\mathrm{VI})-\mathrm{HCOOH}$ solution treated with a Pd@ Polym-MNS-packed reactor, and another that did not receive the treatment. Fixed experimental conditions: $\mathrm{V}=5000 \mathrm{~mL} ;$ Pd@Polym-MNS dose $=0.5 \mathrm{~g} \mathrm{~L}^{-1} ; \mathrm{T}=28^{\circ} \mathrm{C} ;[\mathrm{Cr}(\mathrm{VI})]_{0}=1.0 \mathrm{mM} ;[\mathrm{HCOOH}]_{0}=1000 \mathrm{mM}$.

The positive values of the change in Gibbs free energy of activation $\left(\Delta G^{\ddagger}\right)$ demonstrated that the overall $\mathrm{Cr}(\mathrm{VI})$ conversion process was endergonic or non-spontaneous, which meant that the process lacked the natural tendency to occur without an external driving force in the form of an input of energy or another process coupled to it. The increase in $\Delta G^{\ddagger}$ with increase in temperature shown in Table 4 suggested greater favorability of the $\mathrm{Cr}(\mathrm{VI})$ conversion process at lower temperature. Given that, as detailed in previous studies of the dehydrogenation of $\mathrm{HCOOH}$ on Pd-based catalysts ${ }^{63,64}$, the rate of hydrogen gas generation by adsorbed hydrogen atom recombination following the decarboxylation of $\mathrm{HCOOH}$ (Fig. 2) also increases with increase in temperature, favorability of the $\mathrm{Cr}(\mathrm{VI})$ conversion process at lower temperature could be attributed to diminution of the hydrogen recombination stage of $\mathrm{HCOOH}$ dehydrogenation. The practicability of the Pd@Polym-MNS facilitated Cr(VI) conversion was therefore attributed to the dehydrogenation of $\mathrm{HCOOH}$, which provided the necessary driving force.

Catalysis of porous basket reactor. Reactor efficacy, confirmation of Cr(III) species as the Cr(VI) conversion product, and Pd leaching study. The efficacy of the porous basket reactor mode was investigated by the treatment of a bulk $(5000 \mathrm{~mL})$ solution containing $1.0 \mathrm{mM} \mathrm{Cr}(\mathrm{VI})$ and $1000 \mathrm{mM} \mathrm{HCOOH}$ with a reactor packed with $2.5 \mathrm{~g}$ of Pd@Polym-MNS. As can be observed in Fig. 5, after $720 \mathrm{~min}$ (12 h) of submerging the reactor in the continuously stirred solution, the residual $\mathrm{Cr}(\mathrm{VI})$ had decreased to $2.5 \%$, whereas for a similar mixed $\mathrm{Cr}(\mathrm{VI})$ $\mathrm{HCOOH}$ solution that did not receive treatment with the reactor, the residual $\mathrm{Cr}(\mathrm{VI})$ only dropped to $94.1 \%$ emphasizing the need for the Pd@Polym-MNS to catalyze the Cr(VI) conversion process.

Overwhelming the reactor with large volume of $\mathrm{Cr}(\mathrm{VI})$ solution containing a relatively large initial $\mathrm{Cr}(\mathrm{VI})$ concentration enabled an output of $\mathrm{Cr}$ (III) ions sufficient for the generation of the color associated with the $\mathrm{Cr}(\mathrm{III})$ ions. Accordingly the occurrence of $\mathrm{Cr}(\mathrm{VI})$ reduction in the reactor-treated mixed with $\mathrm{Cr}(\mathrm{VI})-\mathrm{HCOOH}$ solution was evidenced by a gradual change in the color of the solution from yellow to green and then blue. The final blue color was ascribed to the complex formed by the nascent $\mathrm{Cr}$ (III) ions and excess $\mathrm{HCOOH}$, whereas the combination of the $\mathrm{Cr}(\mathrm{III})-\mathrm{HCOOH}$ complex and unreacted $\mathrm{Cr}(\mathrm{VI})$ yielded the transient green color. To gain advantage from the extended period of exposure of the Pd@Polym-MNS to the acidic solution, an aliquot of the final solution was analyzed by ICP-OES whereupon no Pd was detected indicating that there was no leaching in 

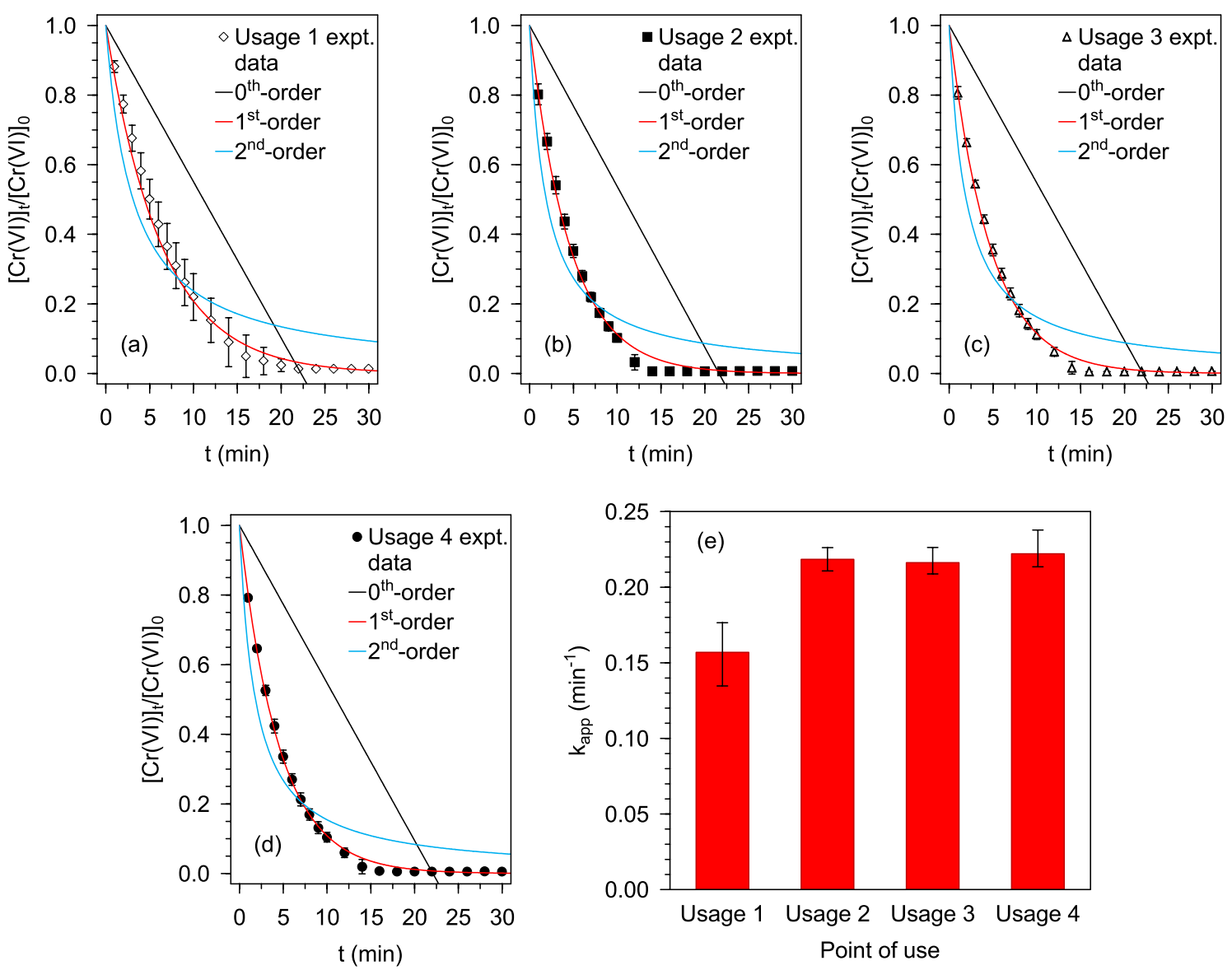

Figure 6. Kinetic plots of remaining fraction of $\mathrm{Cr}(\mathrm{VI})$ versus reaction time for $\mathrm{Cr}(\mathrm{VI})$ reduction by $\mathrm{HCOOH}$ over Pd@Polym-MNS at different points of consedutive reactor use: (a) Usage1, (b) Usage 2, (c) Usage 3, (d) Usage 4. (d) Comparison of the corresponding pparent rate constants. Fixed experimental conditions: $\mathrm{V}=500 \mathrm{~mL} ; \mathrm{Pd} @$ Polym-MNS dose $=5.0 \mathrm{~g} \mathrm{~L}^{-1} ; \mathrm{T}=60^{\circ} \mathrm{C} ;[\mathrm{Cr}(\mathrm{VI})]_{0}=2.0 \mathrm{mM} ;[\mathrm{HCOOH}]_{0}=2000 \mathrm{mM}$.

the acidic conditions that prevailed during the $\mathrm{Cr}(\mathrm{VI})$ conversion process. The absence of Pd leaching in similar applications has previously been reported ${ }^{17,55,65,66}$.

Cr(VI) conversion performance. In order to evaluate the performance of the Pd@Polym-MNS loaded reactor with respect to the reduction of $\mathrm{Cr}(\mathrm{VI})$ using formic acid, and to facilitate comparison with previously reported Pd-based catalyst, a reactor specimen containing $2.5 \mathrm{~g}$ of Pd@Polym-MNS was used to consecutively treat four $500 \mathrm{~mL}$ aliquots of mixed $\mathrm{Cr}(\mathrm{VI})-\mathrm{HCOOH}$ solutions initially containing $2.0 \mathrm{mM} \mathrm{Cr}(\mathrm{VI})$ and $2000 \mathrm{mM} \mathrm{HCOOH}$. Between usages, the basket was stirred in air for $30 \mathrm{~min}$. The obtained kinetic plots of $[\mathrm{Cr}(\mathrm{VI})]_{t} /[\mathrm{Cr}(\mathrm{VI})]_{0}$ versus $t$, which illustrate that pseudo-second-order kinetic model provided best fit to the experimental data in each instance, are presented in Fig. 6a-d $\left(R^{2}=0.9894,0.9949,0.9966,0.9982\right.$ for the first, second, third and fourth usage, respectively). The apparent rate constant as per the pseudo-second-order kinetic model was plotted against the instance of use as shown in Fig. 6e, which depicts an increase in the apparent rate constant from $0.157 \mathrm{~min}^{-1}$ upon the first usage to $0.218 \mathrm{~min}^{-1}$ found for the second usage. Since the redox reaction between the $\mathrm{Cr}(\mathrm{VI})$ and $\mathrm{HCOOH}$ occurred in the adsorbed phase on the surfaces of the Pd@Polym-MNS, the rate reaction was dependent on the quantities of adsorbed $\mathrm{Cr}(\mathrm{VI})$ species and $\mathrm{HCOOH}$. The first usage involved the establishment of the state of adsorption equilibrium, which then presented the highest concentration of adsorbed $\mathrm{Cr}(\mathrm{VI})$ ions. Therefore, the lower pre-equilibrium concentration of adsorbed $\mathrm{Cr}(\mathrm{VI})$ yielded lower rates of $\mathrm{Cr}(\mathrm{VI}) \mathrm{con}$ version on the Pd@Polym-MNS surface.

Moreover, the highest degree of effervescence, which was ascribed to the release of hydrogen gas $\left(\mathrm{H}_{2}\right)$ in addition to $\mathrm{CO}_{2}$, was witnessed during the first usage. We, therefore, posited that in the initial stages of the first usage, the lighter, hence more mobile, $\mathrm{HCOOH}$ molecules with a formula mass of 46.03 amu were more rapidly adsorbed onto the Pd@Polym-MNS surface in comparison to the $\mathrm{HCrO}_{4}{ }^{-}$and $\mathrm{Cr}_{2} \mathrm{O}_{7}{ }^{2-}$ ions with formula masses of $117.00 \mathrm{amu}$ and $215.99 \mathrm{amu}$, respectively. Consequently, the accumulation of adsorbed hydrogen atoms from the decarboxylation of $\mathrm{HCOOH}$ in the presence of a relatively smaller quantity of adsorbed $\mathrm{Cr}(\mathrm{VI})$ ions to participate in redox reactions promoted the formation and desorption of $\mathrm{H}_{2}$ thereby increasing the extent of effervescence in the first usage.

The evened out values of the apparent rate constant values recorded as $0.218 \mathrm{~min}^{-1}, 0.216 \mathrm{~min}^{-1}$ and $0.222 \mathrm{~min}^{-1}$ for the second, third and fourth usages, respectively, indicated that at the end of the first usage the 

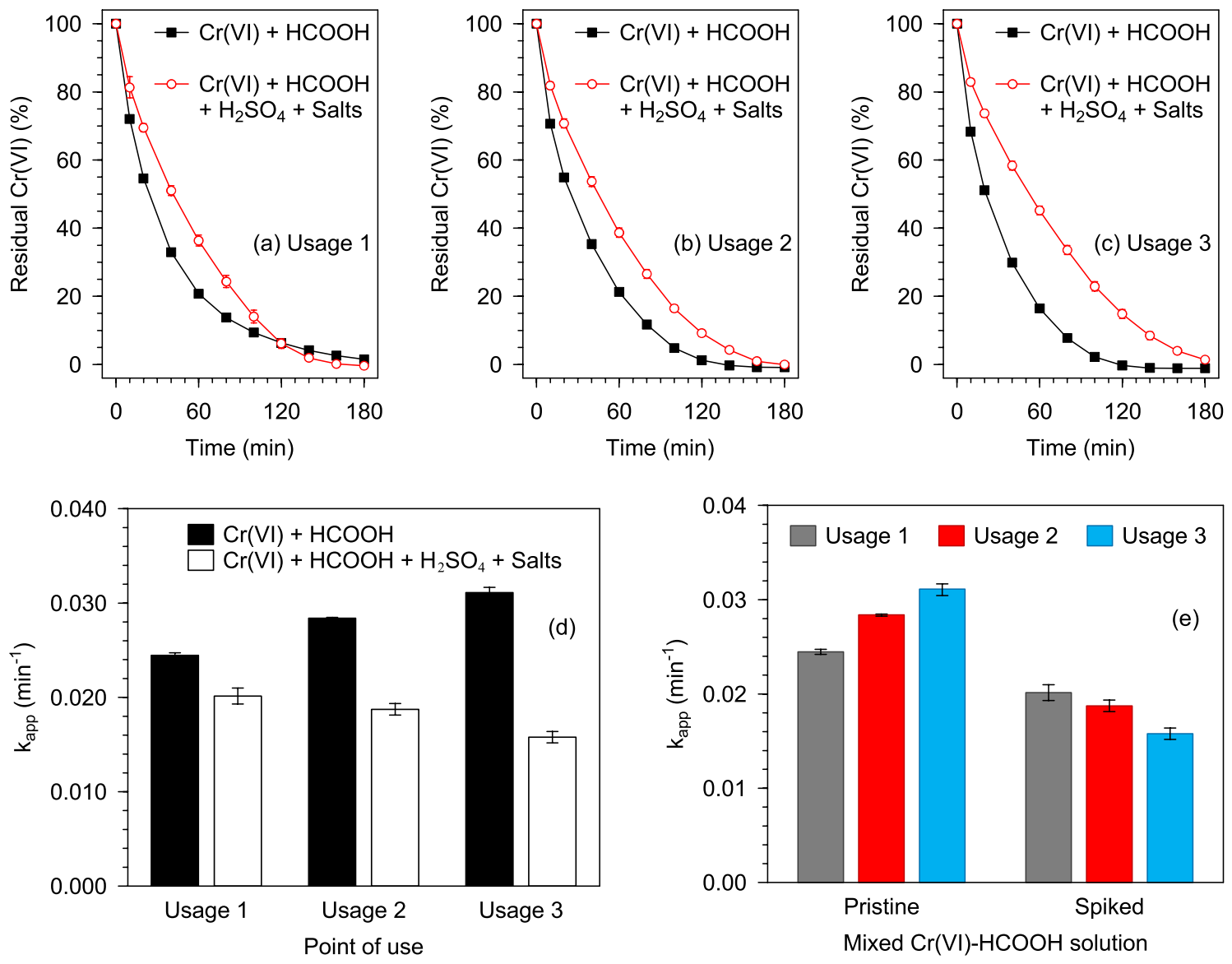

Figure 7. Evolution of the residual $\mathrm{Cr}(\mathrm{VI})$ in pristine and spiked mixed $\mathrm{Cr}(\mathrm{VI})-\mathrm{HCOOH}$ solution treated with a Pd@Polym-MNS-packed reactor at different points of consedutive reactor use: (a) Usage1, (b) Usage 2, (c) Usage 3. (d,e) Comparison of the corresponding apparent rate constants. Fixed experimental conditions: $\mathrm{V}=500 \mathrm{~mL} ; \mathrm{Pd} @$ Polym-MNS dose $=2.0 \mathrm{~g} \mathrm{~L}^{-1} ; \mathrm{T}=50^{\circ} \mathrm{C} ;[\mathrm{Cr}(\mathrm{VI})]_{0}=1.0 \mathrm{mM} ;[\mathrm{HCOOH}]_{0}=200 \mathrm{mM} ;\left[\mathrm{SO}_{4}{ }^{2-}\right.$ ]$_{0}=1000 \mathrm{mM} ;\left[\mathrm{Cl}^{-}\right]_{0}=200 \mathrm{mM} ;\left[\mathrm{NO}_{3}^{-}\right]_{0}=300 \mathrm{mM}$.

quantity of adsorbed $\mathrm{Cr}(\mathrm{VI})$ had increased to the equilibrium level that resulted in a constant rate of the redox reaction with adsorbed hydrogen atoms. The participation of adsorbed hydrogen atoms in the reduction of adsorbed $\mathrm{Cr}(\mathrm{VI})$, as opposed to combination thereby forming $\mathrm{H}_{2}$, was substantiated by the observation of lower extents of effervescence. Furthermore, the plateauing of the apparent rate constant values indicated the stability, hence reusability, of the Pd@Polym-MNS.

Effect of interfering anions. To assess the influence of anionic interference on the activity of the Pd@PolymMNS, two identical reactors were used to consecutively treat three mixed $\mathrm{Cr}(\mathrm{VI})$-HCOOH solutions. The first reactor was used on pristine solutions with no spike reagents whereas the second was applied on solutions spiked with $\mathrm{H}_{2} \mathrm{SO}_{4}(1000 \mathrm{mM}), \mathrm{NaCl}(200 \mathrm{mM})$, and $\mathrm{NaNO}_{3}(300 \mathrm{mM})$ in an attempt to simulate the conditions of electroplating wastewater ${ }^{67}$. After each treatment, the reactor was flushed under running tap water and then soaked in $250 \mathrm{~mL}$ of fresh tap water for $30 \mathrm{~min}$ before the commencement of the next usage. The catalytic activity of the Pd@Polym-MNS in each matching usage was compared by plotting the remaining fraction of Cr(VI) in the solution as presented in Fig. 7a-c. Irrespective of the composition of the mixed $\mathrm{Cr}(\mathrm{VI})-\mathrm{HCOOH}$ solution, less than $2 \%$ of the initial Cr(VI) remained in the solution after 180 min of contact with the Pd@Polym-MNS in all three instances of usage. However, for the first two-thirds of the first usage (up to $120 \mathrm{~min}$ ) as well as the entirety of the second and third usages, the residual $\mathrm{Cr}(\mathrm{VI})$ proportion at a particular time was higher in the spiked solutions than in the pristine solutions, which is reflected by the comparison of the corresponding apparent rate constant values derived from fitting the pseudo-second-order model equation (Fig. 7d). In addition to the adsorption of $\mathrm{Cr}(\mathrm{VI})$ ions onto the Pd@Polym-MNS surface, there was competitive uptake of the co-existing $\mathrm{SO}_{4}{ }^{2-}, \mathrm{Cl}^{-}$ and $\mathrm{NO}_{3}{ }^{-}$ions from the spiked mixed $\mathrm{Cr}(\mathrm{VI})-\mathrm{HCOOH}$ solutions. Consequently, the quantity of $\mathrm{Cr}(\mathrm{VI})$ ions adsorbed from the spiked solutions was lower than that from the pristine solutions hence the lower rated rates of $\mathrm{Cr}(\mathrm{VI})$ conversion signified by the lower apparent rate constants.

Since the spike reagents were present in large concentrations, the Pd@Polym-MNS surface became extensively covered by $\mathrm{SO}_{4}{ }^{2-}, \mathrm{Cl}^{-}$and $\mathrm{NO}_{3}{ }^{-}$ions during the first usage. Therefore, the majority of the adsorption sites that were available for the uptake of $\mathrm{Cr}(\mathrm{VI})$ ions in the subsequent usages were those from which nascent $\mathrm{Cr}(\mathrm{III})$ ions were desorbed. However, in the prevailing conditions of high $\mathrm{SO}_{4}{ }^{2-}, \mathrm{Cl}^{-}$and $\mathrm{NO}_{3}{ }^{-}$ion concentration, the greater 


\begin{tabular}{|c|c|c|c|c|c|c|}
\hline \multirow[b]{2}{*}{ Run no } & \multirow[b]{2}{*}[\mathrm{Cr}(\mathrm{VI})]{$_{0}(\mathrm{mM})$} & \multirow[b]{2}{*}[\mathrm{HCOOH}]{$_{0}(\mathrm{mM})$} & \multirow[b]{2}{*}{ Dose $\left(\mathrm{g} \mathrm{L}^{-1}\right)$} & \multirow[b]{2}{*}{$\mathrm{T}\left({ }^{\circ} \mathrm{C}\right)$} & \multicolumn{2}{|c|}{ Response, $\mathrm{k}\left(\mathrm{min}^{-1}\right)$} \\
\hline & & & & & Observed & Predicted \\
\hline 1 & 1.5 & 100 & 1 & 25 & 0.00459 & 0.00379 \\
\hline 2 & 1.5 & 100 & 1 & 45 & 0.00794 & 0.00688 \\
\hline 3 & 1.5 & 100 & 3 & 25 & 0.01202 & 0.01224 \\
\hline 4 & 1.5 & 100 & 3 & 45 & 0.02325 & 0.02494 \\
\hline 5 & 1.5 & 300 & 1 & 25 & 0.00577 & 0.00680 \\
\hline 6 & 1.5 & 300 & 1 & 45 & 0.01149 & 0.01235 \\
\hline 7 & 1.5 & 300 & 3 & 25 & 0.02140 & 0.02163 \\
\hline 8 & 1.5 & 300 & 3 & 45 & 0.03708 & 0.03679 \\
\hline 9 & 2.5 & 100 & 1 & 25 & 0.00236 & 0.00353 \\
\hline 10 & 2.5 & 100 & 1 & 45 & 0.00689 & 0.00628 \\
\hline 11 & 2.5 & 100 & 3 & 25 & 0.01197 & 0.01074 \\
\hline 12 & 2.5 & 100 & 3 & 45 & 0.02325 & 0.02310 \\
\hline 13 & 2.5 & 300 & 1 & 25 & 0.00478 & 0.00271 \\
\hline 14 & 2.5 & 300 & 1 & 45 & 0.00727 & 0.00793 \\
\hline 15 & 2.5 & 300 & 3 & 25 & 0.01435 & 0.01628 \\
\hline 16 & 2.5 & 300 & 3 & 45 & 0.03068 & 0.03111 \\
\hline 17 & 0.5 & 200 & 2 & 35 & 0.01827 & \begin{tabular}{|l|l|}
0.01790 \\
\end{tabular} \\
\hline 18 & 3 & 200 & 2 & 35 & 0.01116 & 0.01149 \\
\hline 19 & 2 & 50 & 2 & 35 & 0.00796 & 0.00925 \\
\hline 20 & 2 & 500 & 2 & 35 & 0.01655 & \begin{tabular}{|l|l|}
0.01601 \\
\end{tabular} \\
\hline 21 & 2 & 200 & 0.5 & 35 & 0.00195 & 0.00326 \\
\hline 22 & 2 & 200 & 5 & 35 & 0.03899 & 0.03844 \\
\hline 23 & 2 & 200 & 2 & 15 & 0.00640 & 0.00642 \\
\hline 24 & 2 & 200 & 2 & 55 & 0.02485 & 0.02433 \\
\hline 25 & 2 & 200 & 2 & 35 & 0.01574 & 0.01527 \\
\hline 26 & 2 & 200 & 2 & 35 & 0.01592 & \begin{tabular}{|l|l|}
0.01527 \\
\end{tabular} \\
\hline 27 & 2 & 200 & 2 & 35 & 0.01688 & 0.01527 \\
\hline 28 & 2 & 200 & 2 & 35 & 0.01598 & 0.01527 \\
\hline 29 & 2 & 200 & 2 & 35 & 0.01559 & 0.01527 \\
\hline 30 & 2 & 200 & 2 & 35 & 0.01445 & \begin{tabular}{|l|}
0.01527 \\
\end{tabular} \\
\hline
\end{tabular}

Table 5. Central composite design matrix and experimental results for $\mathrm{HCOOH}$-mediated $\mathrm{Cr}(\mathrm{VI})$ conversion on Pd@Polym-MNS.

part of the vacated adsorption sites proceeded to be occupied by the co-existing ions. Ultimately, the quantity of adsorbed $\mathrm{Cr}(\mathrm{VI})$ ions continuously decreased with consecutive use of the Pd@Polym-MNS as indicated by the continuous decrease in the rate constant for $\mathrm{Cr}(\mathrm{VI})$ conversion in the spiked solutions as depicted by Fig. 7e. Treatment of the pristine solutions yielded a successive increase in the value of the rate constant indicating successive increases in the rate of $\mathrm{Cr}(\mathrm{VI})$ conversion thereby suggesting that succeeding usages involved larger quantities of adsorbed $\mathrm{Cr}(\mathrm{VI})$ ions. Successive increase in the quantity of adsorbed $\mathrm{Cr}(\mathrm{VI})$ ions pointed to incomplete coverage of the Pd@Polym-MNS surface by the Cr(VI) ions. Therefore, additional uptake of Cr(VI) ions on vacant sites on the Pd@Polym-MNS surface upon the introduction of fresh mixed $\mathrm{Cr}(\mathrm{VI})-\mathrm{HCOOH}$ solution in the next usage resulted in an increase in the quantity of adsorbed $\mathrm{Cr}(\mathrm{VI})$ ions available for redox reaction with active hydrogen atoms adsorbed on the Pd surface, which, in turn, increased the rate of $\mathrm{Cr}(\mathrm{VI})$ conversion.

Response surface methodological modeling of reactor performance. The results obtained from the central composite design-based experiments are summarized in Table 5 wherein the responses of the center point experiment (run numbers 25-30) exhibited a coefficient of variation of 4.9\%, which indicated a desirable level of reproducibility and accuracy of the experiments. The model equation relating the apparent rate constant $\left(k_{a p p}\right)$ to the initial $\mathrm{Cr}(\mathrm{VI})$ concentration $\left([\mathrm{Cr}(\mathrm{VI})]_{0}\right)$, initial HCOOH concentration $\left([\mathrm{HCOOH}]_{0}\right)$, Pd@Polym-MNS dose (Dose), and temperature $(T)$ was found to be as follows:

$$
\begin{aligned}
k_{a p p}= & -0.0061536+0.0059316[\mathrm{Cr}(\mathrm{VI})]_{0}+0.0000460[\mathrm{HCOOH}]_{0}-0.0021801 \text { Dose } \\
& -0.0001409 \mathrm{~T}-0.0000192[\mathrm{Cr}(\mathrm{VI})]_{0}[\mathrm{HCOOH}]_{0}-0.0006250[\mathrm{Cr}(\mathrm{VI})]_{0} \text { Dose }-0.0000168 \\
& {[\mathrm{Cr}(\mathrm{VI})]_{0} \mathrm{~T}+0.0000159[\mathrm{HCOOH}]_{0} \text { Dose }+0.0000006[\mathrm{HCOOH}]_{0} T+0.0002401 \text { Dose } T } \\
& -0.0008071[\mathrm{Cr}(\mathrm{VI})]_{0}^{2}-0.0000001[\mathrm{HCOOH}]_{0}^{2}-0.0000619 \text { Dose }^{2}+0.0000003 T^{2}
\end{aligned}
$$



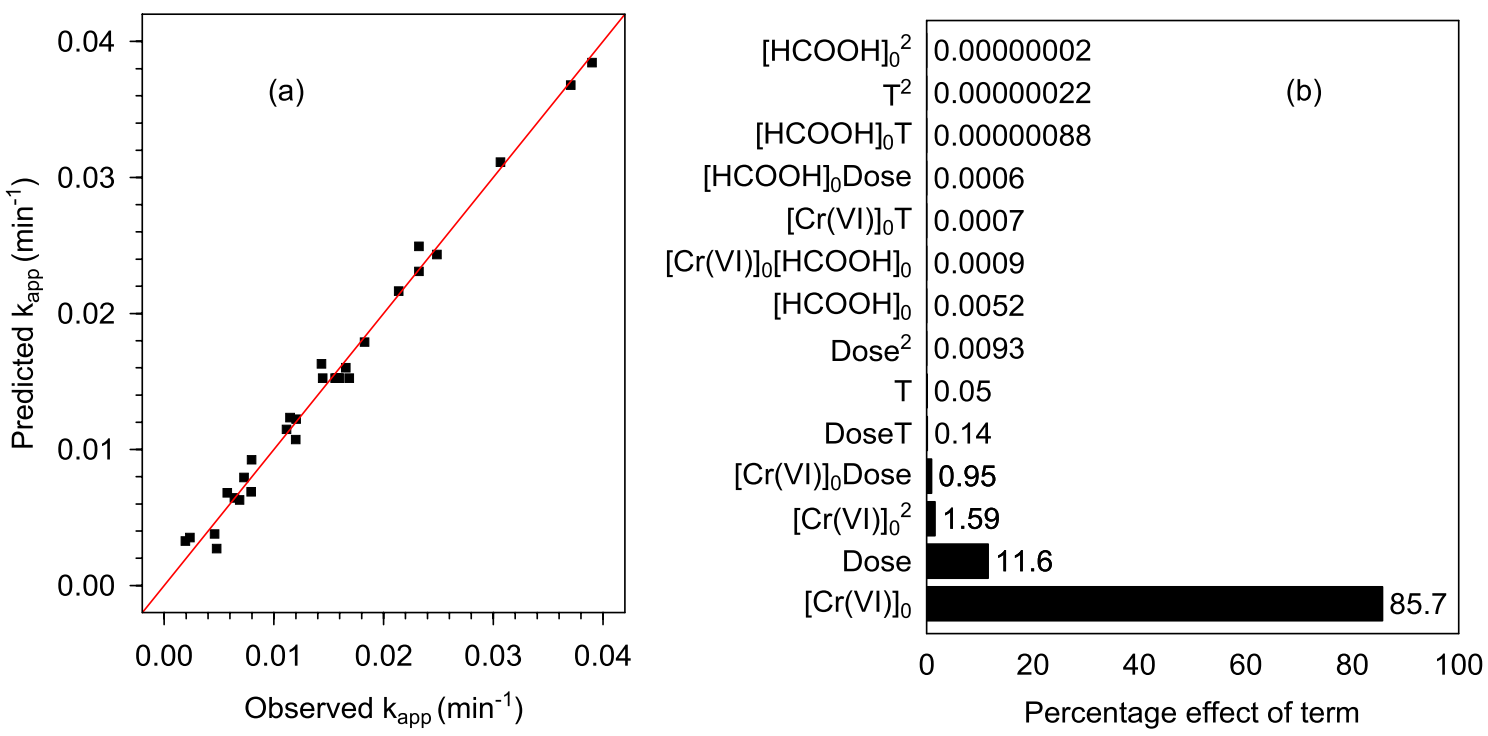

Figure 8. (a) Parity plot of observed versus predicted apparent rate constant values, and (b) Pareto plot of percentage effects for the developed response surface methodology-based model for $\mathrm{Cr}(\mathrm{VI})$ reduction by $\mathrm{HCOOH}$ in a Pd@Polym-MNS packed in a porous basket reactor.

\begin{tabular}{|l|l|l|l|l|l|}
\hline Variance source & Sum of squares & Degree of freedom & Mean square & F-value & $\mathbf{F}_{\text {crit }}$ \\
\hline Regression & 0.002547 & 14 & 0.0001819 & 98.95 & 2.424 \\
\hline Residues & 0.000028 & 15 & 0.0000018 & & \\
\hline Total & 0.002575 & 29 & & & \\
\hline
\end{tabular}

Table 6. Analysis of variance for the regression-modeled rate constant for $\mathrm{HCOOH}$-mediated $\mathrm{Cr}(\mathrm{VI})$ conversion on Pd@Polym-MNS.

The agreement of the observed apparent rate constant values with those predicted by Eq. (20) was exhibited by the distribution of the data about the $\mathrm{x}=\mathrm{y}$ line as shown in Fig. 8a. Using the coefficients of the model equation, the percentage effect of each term on the value of the predicted rate constant, $P_{i}(\%)$, was calculated using Eq. (21) expressed as:

$$
\mathrm{P}_{\mathrm{i}}=\frac{\mathrm{b}_{\mathrm{i}}^{2}}{\sum \mathrm{b}_{\mathrm{i}}^{2}} \times 100 \%
$$

where $b_{i}$ (dimensionless) coefficient of term $i^{68}$. As shown in Fig. $8 \mathrm{~b}$ the initial Cr(VI) concentration and Pd@ Polym-MNS, accounting for $85.7 \%$ and $11.6 \%$, respectively, produced the greatest effect on the rate of Cr(VI) conversion, demonstrating that the reaction heavily depended on the adsorption of the Cr(VI) ions on the Pd@ Polym-MNS.

Analysis of variance (ANOVA), based on testing the null hypothesis that the developed regression model fitted the data well against the alternative hypothesis that the model did not provide a good fit to the experimental data, was conducted (Table 6). The $F$-value of the regression procedure, which was found to be 98.95 , was higher than the critical F-value at a significance level of 0.05 (2.424). Therefore, statistical significance, corresponding to the lack of support for the null hypothesis, was reached. The coefficient of determination $\left(R^{2}\right)$ was 0.9893 indicating a good correlation between observed and model-predicted values of the first-order rate constant as shown in Fig. 8a. Accordingly, the model was deemed sufficient for the generation of response surface plots and subsequent analysis of the combined influence of the input variables.

The response surface plots showing the influences of different combinations of the input variables on the rate constant for $\mathrm{Cr}(\mathrm{VI})$ conversion on the Pd@Polym-MNS are presented in Fig. 9. Varying the Cr(VI) concentration at low $\mathrm{HCOOH}$ concentration had little impact on the rate constant (Fig. 9a). However, at high $\mathrm{HCOOH}$ concentration, the rate constant decreased with increasing $\mathrm{Cr}(\mathrm{VI})$ concentration. At any given $\mathrm{Cr}(\mathrm{VI})$ concentration, the value of the rate constant increased with increasing $\mathrm{HCOOH}$ concentration. The greatest impact of increasing the $\mathrm{HCOOH}$ concentration was at low $\mathrm{Cr}(\mathrm{VI})$ concentration where the value of the rate constant increased more rapidly. Therefore, the combined effect of the initial concentrations of $\mathrm{Cr}(\mathrm{VI})$ and $\mathrm{HCOOH}$ had the greatest impact at low $\mathrm{Cr}(\mathrm{VI})$ concentration and high $\mathrm{HCOOH}$ concentration.

While as shown by Fig. 9b,c, varying the initial Cr(VI) concentration at any Pd@Polym-MNS dose or temperature had no impact on the rate constant, neither the increase in Pd@Polym-MNS dose nor temperature at any $\mathrm{Cr}(\mathrm{VI})$ concentration yielded higher values of the rate constant. Therefore, neither the combination of initial 

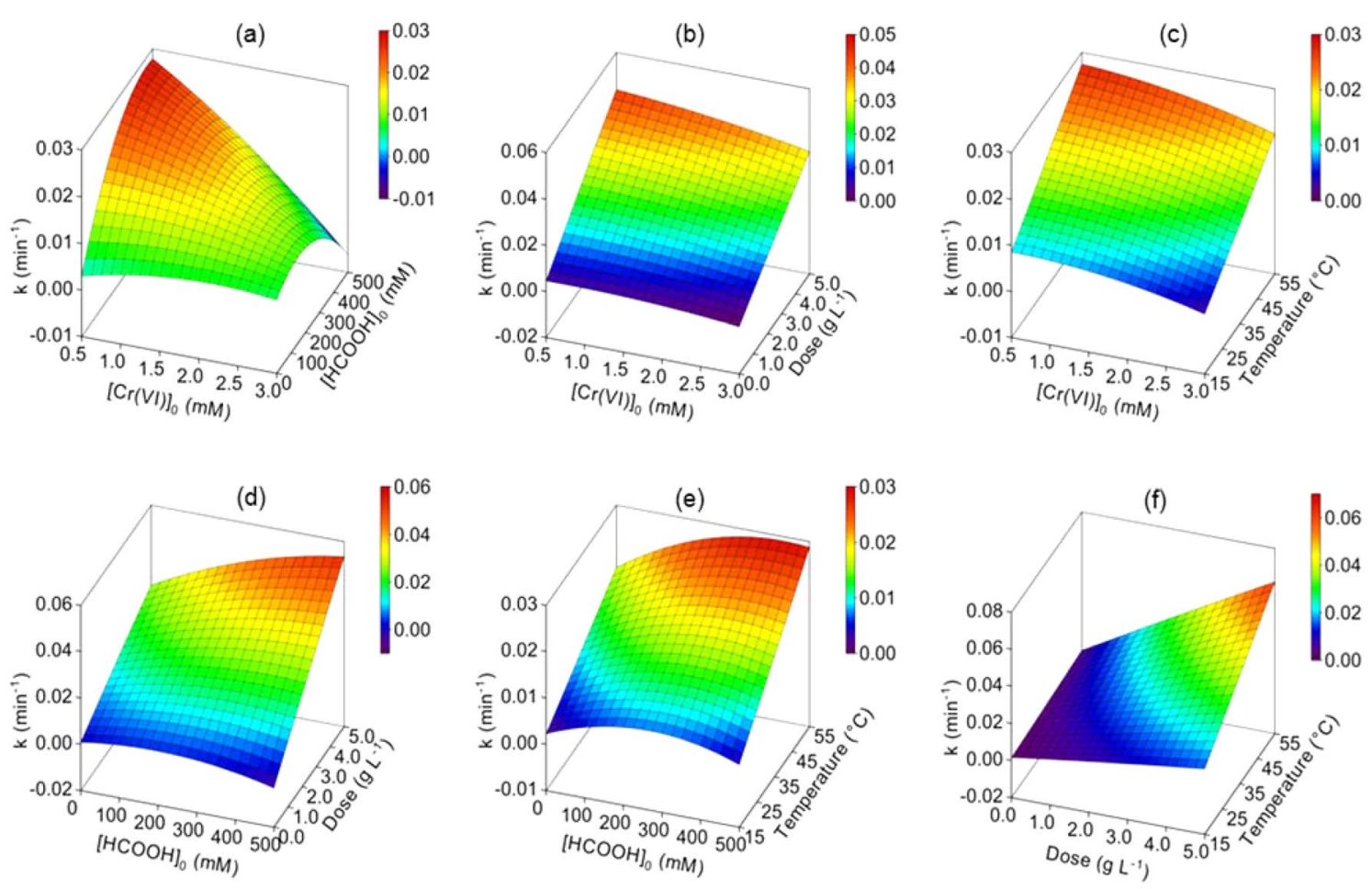

Figure 9. Response surface plots showing the combined effects of (a) initial $\mathrm{Cr}(\mathrm{VI})$ concentration and initial HCOOH concentration, (b) initial Cr(VI) concentration and Pd@Polym-MNS dose, (c) initial Cr(VI) concentration and temperature, (d) initial HCOOH concentration and Pd@Polym-MNS dose, (e) initial $\mathrm{HCOOH}$ concentration and temperature, and (f) Pd@Polym-MNS dose and temperature on Cr(VI) reduction by HCOOH over Pd@Polym-MNS packed in a porous basket reactor.

Cr(VI) concentration and Pd@Polym-MNS dose nor initial Cr(VI) concentration and the temperature had a mutual influence on the rate of $\mathrm{Cr}(\mathrm{VI})$ conversion. According to Fig. 9d, varying the initial HCOOH concentration at low Pd@Polym-MNS dose had little effect on the value of the rate constant. Conversely, at high Pd@PolymMNS dose, increasing the initial $\mathrm{HCOOH}$ concentration resulted in an increase in the rate constant. Although increasing the Pd@Polym-MNS dose at any initial $\mathrm{HCOOH}$ concentration resulted in the higher rate constant values, the increase at lower $\mathrm{HCOOH}$ concentration was less rapid than at higher $\mathrm{HCOOH}$ concentration. Therefore, the initial HCOOH concentration and Pd@Polym-MNS dose had a combined effect on the Cr(VI) conversion rate whereupon high values of both input variables resulted in amplified values of the rate constant.

Although increasing the temperature at any $\mathrm{HCOOH}$ concentration yielded an increase in the value of the rate constant, changing the initial $\mathrm{HCOOH}$ concentration at a given temperature had a minor impact on the rate constant (Fig. 9e). Therefore, the combination of initial HCOOH concentration and the temperature had little influence on the rate of $\mathrm{Cr}(\mathrm{VI})$ conversion. Though, as per Fig. 9f, increasing the Pd@Polym-MNS dose at a low temperature slightly increased the value of the rate constant, a similar increase in the Pd@Polym-MNS dose at higher temperature resulted in a greater increase in the rate constant value. Likewise, the increase in the value of the rate constant with increasing temperature was more intense at higher Pd@Polym-MNS dose indicating the existence of a mutual influence of these input variables.

Comparison of reactor performance with that of suspended Pd@Polym-MNS and other catalysts. Owing to the adverse effects of aggregation, which results in less effective exposure of the Pd@PolymMNS packed in the basket reactor to the mixed $\mathrm{Cr}(\mathrm{VI})-\mathrm{HCOOH}$ solution, it was anticipated that the performance of the basket-restrained Pd@Polym-MNS would be lesser than that of the freely suspended Pd@Polym-MNS. In order to facilitate comparison of the performance of the Pd@Polym-MNS in the freely suspended and basketrestrained modes, Eq. (20), the equation of the model as derived by response surface methodology, was used for the prediction of the apparent rate constant values that the basket reactor would yield under the conditions of the thermodynamic parameter determination experiments in which freely suspended Pd@Polym-MNS was used. Figure 10 compares the experimentally determined apparent rate constant values to the predictions of the RSM-derived model at the different incubation temperatures used upon the thermodynamic parameter determination experiments.

At each of the five temperatures, there was an evident discrepancy between the two apparent rate constants. The attenuated apparent rate constant values predicted for the basket-restrained Pd@Polym-MNS were 73.8\% to $84.4 \%$ lower than the values recorded when the freely suspended Pd@Polym-MNS was used. However, it is noteworthy that, as shown in Table 7, the highest apparent rate constant value recorded as $0.222 \mathrm{~min}^{-1}$ for the basket-restrained Pd@Polym-MNS was higher than previously reported values noted for Cr(VI) reduction 


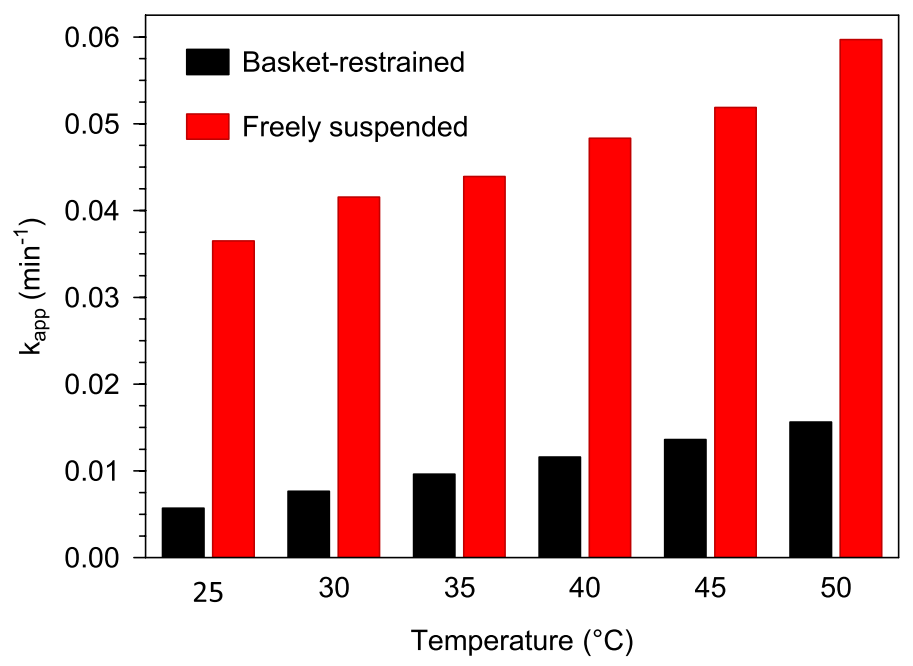

Figure 10. Comparison of apparent rate constant values obtained at different temperatures for $\mathrm{Cr}(\mathrm{VI})$ reduction by HCOOH over freely suspended Pd@Polym-MNS to predicted values for reduction in a Pd@ Polym-MNS packed in a porous basket reactor.

\begin{tabular}{|l|l|l|}
\hline Catalyst & $\mathbf{k}_{\text {app }}\left(\mathbf{m i n}^{-1}\right)$ & Reference \\
\hline Polyethersulfone bead-immobilized Pd nanoparticles & 0.167 & 17 \\
\hline PdCu nanoboxes & 0.274 & 18 \\
\hline Amino-functionalized Pd nanowires & 0.282 & 69 \\
\hline Pd nanocrystals supported on reduced graphene oxide & 0.0785 & 70 \\
\hline Polyurea microsphere immobilized Pd & 0.123 & 71 \\
\hline Pd nanoparticles immobilized on procyanidin-grafted eggshell membrane & 0.133 & 72 \\
\hline Magnetic mesoporous carbon doped with Pd nanoparticles & 0.267 & 73 \\
\hline Pd decorated carbon nanotubes & 0.310 & 74 \\
\hline $\mathrm{Fe}_{3} \mathrm{O}_{4} /$ Pd nanoparticles encapsulated in nitrogen-doped carbon & 0.300 & 75 \\
\hline Macadamia nutshell-supported Pd nanoparticles (Pd@Polym-MNS) & 0.222 & This work \\
\hline
\end{tabular}

Table 7. Rate constant values of $\mathrm{HCOOH}$-assisted $\mathrm{Cr}(\mathrm{VI})$ conversion on different Pd-loaded materials.

processes catalyzed by a few Pd-based materials including polyethersulfone bead-immobilized Pd nanoparticles and Pd nanocrystals supported on reduced graphene oxide. The majority of examples listed in Table 7 illustrated comparable performance to that of the Pd@Polym-MNS.

\section{Conclusions}

Zerovalent palladium impregnated in polymer-grafted Macadamia nutshell biomass packed in a porous basket reactor to enhance the ease of recovery for recurrent use provides a reactor that adsorbs aqueous $\operatorname{Cr}(\mathrm{VI})$ species and formic acid molecules. Thereafter, the formic acid adsorbed on the palladium decomposes and generates reactive hydrogen species that undergo a redox reaction with the adsorbed $\mathrm{Cr}(\mathrm{VI})$ species resulting in the conversion of $\mathrm{Cr}(\mathrm{VI})$ to $\mathrm{Cr}(\mathrm{III})$. The naturally acidic conditions that prevail in the presence of the formic acid ensure that a large proportion of the nascent $\mathrm{Cr}$ (III) ions is desorbed from the catalyst surface thereby preventing catalyst deactivation. According to weighted Pareto analysis of the coefficients of a fitted response surface methodological model that relates the apparent rate constant of the $\mathrm{Cr}(\mathrm{VI})$ conversion process to initial $\mathrm{Cr}(\mathrm{VI})$ concentration, initial formic acid concentration, catalyst dosage and solution temperature, which have the highest impact on the performance of the porous basket reactor, initial $\mathrm{Cr}(\mathrm{VI})$ concentration and catalyst dosage account for the largest proportion of the observed changes in the value of the apparent rate constant. The results of this study demonstrate that simple reactors with competitive catalytic activity can be constructed using wire mesh that not only allows easy separation of the catalyst from the treated solution but also helps prevent damage of the catalyst particles by collisions amongst themselves, and with stirrer blades and container walls. The study sets the pace for the development of similarly built reactors with modifications that minimize catalyst aggregation and enhance the exposure of the restrained catalyst to the solution requiring treatment. 
Received: 4 September 2021; Accepted: 30 November 2021

Published online: 17 December 2021

\section{References}

1. Chen, Z. et al. Involvement of a novel regulatory cascade consisting of SET-H3K18ac/H3K27ac-53BP1 in Cr(VI)-induced malignant transformation of 16HBE cells. Toxicol. Lett. 339, 70-77 (2021).

2. Zhang, B. et al. Selenium(IV) alleviates chromium(VI)-induced toxicity in the green alga Chlamydomonas reinhardtii. Environ. Pollut. 272, 116407 (2021).

3. Vincent, J. B. Beneficial effects of chromium(III) and vanadium supplements in diabetes. in Nutritional and Therapeutic Interventions for Diabetes and Metabolic Syndrome (eds. Bagchi, D. \& Nair, S.). 365-374. (Academic Press, 2018).

4. Shahnaz, T., Patra, C., Sharma, V. \& Selvaraju, N. A comparative study of raw, acid-modified and EDTA-complexed Acacia auriculiformis biomass for the removal of hexavalent chromium. Chem. Ecol. 36, 360-381 (2020).

5. Mpouras, T., Polydera, A., Dermatas, D., Verdone, N. \& Vilardi, G. Multi wall carbon nanotubes application for treatment of $\mathrm{Cr}(\mathrm{VI})$-contaminated groundwater; Modeling of batch \& column experiments. Chemosphere 269, 128749 (2021)

6. Kumar, S., Shahnaz, T., Selvaraju, N. \& Rajaraman, P. V. Kinetic and thermodynamic studies on biosorption of Cr(VI) on raw and chemically modified Datura stramonium fruit. Environ. Monit. Assess. 192, 248 (2020).

7. Han, A., Zhang, H., Sun, J., Chuah, G.-K. \& Jaenicke, S. Investigation into bulk liquid membranes for removal of chromium(VI) from simulated wastewater. J. Water Process Eng. 17, 63-69 (2017).

8. Ying, Z. et al. Separation and recovery vanadium(V) and chromium (VI) using amide extractants based on the steric hindrance effect. J. Environ. Chem. Eng. 9, 105939 (2021).

9. Choudhury, P., Mondal, P., Majumdar, S., Saha, S. \& Sahoo, G. C. Preparation of ceramic ultrafiltration membrane using green synthesized $\mathrm{CuO}$ nanoparticles for chromium(VI) removal and optimization by response surface methodology. J. Clean. Prod. 203, 511-520 (2018).

10. Gebru, K. A. \& Das, C. Removal of chromium(VI) ions from aqueous solutions using amine-impregnated $\mathrm{TiO} 2$ nanoparticles modified cellulose acetate membranes. Chemosphere 191, 673-684 (2018).

11. Wu, J. et al. Preparation of highly dispersive and antioxidative nano zero-valent iron for the removal of hexavalent chromium. Chemosphere 262, 127733 (2021).

12. Aggarwal, R., Saini, D., Sonkar, S. K., Sonker, A. K. \& Westman, G. Sunlight promoted removal of toxic hexavalent chromium by cellulose derived photoactive carbon dots. Chemosphere 287, 132287 (2022).

13. Pattappan, D., Kavya, K. V., Vargheese, S., Kumar, R. T. R. \& Haldorai, Y. Graphitic carbon nitride/NH2-MIL-101(Fe) composite for environmental remediation: Visible-light-assisted photocatalytic degradation of acetaminophen and reduction of hexavalent chromium. Chemosphere 286, 131875 (2022).

14. Zhao, Y. et al. Reduced graphene oxide supported $\mathrm{ZnO} / \mathrm{CdS}$ heterojunction enhances photocatalytic removal efficiency of hexavalent chromium from aqueous solution. Chemosphere 286, 131738 (2022).

15. Luo, L., Dong, S., Cui, H., Sun, L. \& Huang, T. Indium sulfide deposited MIL-53(Fe) microrods: Efficient visible-light-driven photocatalytic reduction of hexavalent chromium. J. Colloid Interface Sci. 606, 1299-1310 (2022).

16. Zhu, K. et al. MOFs-induced encapsulation of ultrafine Ni nanoparticles into 3D N-doped graphene-CNT frameworks as a recyclable catalyst for $\mathrm{Cr}(\mathrm{VI})$ reduction with formic acid. Carbon 148, 52-63 (2019).

17. Markad, U. S., Naik, D. B., Singh, K. K., Kumar, M. \& Sharma, G. K. Immobilisation of palladium nanostructures in polyethersulfone beads: recyclable catalyst for chromium(VI) remediation. Environ. Chem. 16, 622-629 (2019).

18. Qiao, B. et al. Facile synthesis of porous PdCu nanoboxes for efficient chromium(VI) reduction. CrystEngComm 21, 3654-3659 (2019).

19. Montero, M. A., Luque, G. C., de Chialvo, M. R. G. \& Chialvo, A. C. Kinetic evaluation of the formic acid electrooxidation on steady state on palladium using a flow cell. J. Electroanal. Chem. 879, 114777 (2020).

20. Lv, Z. et al. Metal-organic frameworks-derived 3D yolk shell-like structure Ni@carbon as a recyclable catalyst for $\mathrm{Cr}(\mathrm{VI})$ reduction. Chem. Eng. J. 389, 123428 (2020).

21. Markad, U. S. et al. Photo enhanced detoxification of chromium(VI) by formic acid using 3D palladium nanocatalyst. J. Photochem. Photobiol. A Chem. 338, 115-122 (2017).

22. Santos, J. L., Megias-Sayago, C., Ivanova, S., Centeno, M. A. \& Odriozola, J. A. Functionalized biochars as supports for Pd/C catalysts for efficient hydrogen production from formic acid. Appl. Catal. B Environ. 282, 119615 (2021).

23. Teng, Z. et al. Facile synthesis of channel-rich ultrathin palladium-silver nanosheets for highly efficient formic acid electrooxidation. Mater. Today Energy 19, 100596 (2021).

24. Barlocco, I. et al. Synthesis of palladium-rhodium bimetallic nanoparticles for formic acid dehydrogenation. J. Energy Chem. 52, 301-309 (2021)

25. Li, X. et al. Self-limiting synthesis of Au-Pd core-shell nanocrystals with a near surface alloy and monolayer Pd shell structure and their superior catalytic activity on the conversion of hexavalent chromium. Appl. Catal. B Environ. 253, 263-270 (2019).

26. Zhang, Z., Sun, L. \& Liu, R. Flash nanoprecipitation of polymer supported Pt colloids with tunable catalytic chromium reduction property. Colloid Polym. Sci. 296, 327-333 (2018).

27. Xu, T., Xue, J., Zhang, X., He, G. \& Chen, H. Ultrafine cobalt nanoparticles supported on reduced graphene oxide: Efficient catalyst for fast reduction of hexavalent chromium at room temperature. Appl. Surf. Sci. 402, 294-300 (2017).

28. Tripathi, R. M., Rao, R. P. \& Tsuzuki, T. Green synthesis of sulfur nanoparticles and evaluation of their catalytic detoxification of hexavalent chromium in water. RSC Adv. 8, 36345-36352 (2018).

29. Hou, S. et al. Remediation performance and mechanism of hexavalent chromium in alkaline soil using multi-layer loaded nanozero-valent iron. Environ. Pollut. 252, 553-561 (2019).

30. Liu, W. et al. Insight into $\mathrm{pH}$ dependent $\mathrm{Cr}(\mathrm{VI})$ removal with magnetic Fe3S4. Chem. Eng. J. 359, 564-571 (2019).

31. Ren, G. et al. Chromium (VI) adsorption from wastewater using porous magnetite nanoparticles prepared from titanium residue by a novel solid-phase reduction method. Sci. Total Environ. 607-608, 900-910 (2017).

32. Zhang, W. et al. Synergistic roles of Fe(II) on simultaneous removal of hexavalent chromium and trichloroethylene by attapulgitesupported nanoscale zero-valent iron/persulfate system. Chem. Eng. J. 430, 132841 (2022).

33. Zou, H. et al. Ball milling biochar iron oxide composites for the removal of chromium $(\mathrm{Cr}(\mathrm{VI}))$ from water: Performance and mechanisms. J. Hazard. Mater. 413, 125252 (2021).

34. Wen, J., Xue, Z., Yin, X. \& Wang, X. Insights into aqueous reduction of $\mathrm{Cr}(\mathrm{VI})$ by biochar and its iron-modified counterpart in the presence of organic acids. Chemosphere 286, 131918 (2022).

35. Xie, Y., Lu, G., Tao, X., Wen, Z. \& Dang, Z. A collaborative strategy for elevated reduction and immobilization of Cr(VI) using nano zero valent iron assisted by schwertmannite: Removal performance and mechanism. J. Hazard. Mater. 422, 126952 (2022).

36. Cao, R. et al. Enhanced remediation of $\mathrm{Cr}(\mathrm{VI})$-contaminated groundwater by coupling electrokinetics with $\mathrm{ZVI} / \mathrm{Fe} 3 \mathrm{O} 4 / \mathrm{AC}$-based permeable reactive barrier. J. Environ. Sci. 112, 280-290 (2022).

37. Zhang, S., Lee, Y.-R., Jeon, H.-J., Ahn, W.-S. \& Chung, Y.-M. Pd nanoparticles on a microporous covalent triazine polymer for H2 production via formic acid decomposition. Mater. Lett. 215, 211-213 (2018). 
38. Sanchez, F. et al. Hydrogen production from formic acid decomposition in the liquid phase using Pd nanoparticles supported on CNFs with different surface properties. Sustain. Energy Fuels 2, 2705-2716 (2018).

39. Kokkinos, E. \& Zouboulis, A. A step by step investigation of Cr(III) recovery from tannery waste. Proceedings 48, 6436 (2020).

40. Minas, F., Chandravanshi, B. S. \& Leta, S. Chemical precipitation method for chromium removal and its recovery from tannery wastewater in Ethiopia. Chem. Int. 3, 291-305 (2017).

41. Li, D.-N. et al. Uniform Pt@Pd nanocrystals supported on N-doped reduced graphene oxide as catalysts for effective reduction of highly toxic chromium(VI). Mater. Chem. Phys. 205, 64-71 (2018).

42. Gao, Y., Sun, W., Yang, W. \& Li, Q. Palladium nanoparticles supported on amine-functionalized glass fiber mat for fixed-bed reactors on the effective removal of hexavalent chromium by catalytic reduction. J. Mater. Sci. Technol. 34, 961-968 (2017).

43. Misra, N. et al. Mitigation of $\mathrm{Cr}(\mathrm{VI})$ toxicity using Pd-nanoparticles immobilized catalytic reactor (Pd-NICaR) fabricated via plasma and gamma radiation. Environ. Sci. Pollut. Res. 25, 16101-16110 (2018).

44. Wang, W. et al. Biosynthesis of palladium nanoparticles using Shewanella loihica PV-4 for excellent catalytic reduction of chromium(VI). Environ. Sci. Nano 5, 730-739 (2018).

45. Bai, L. et al. Cyclodextrin-assisted synthesis of Pd/Co/C nanopolyhedra by ZIF-67 as a highly acid tolerant catalyst for hexavalent chromium reduction. Inorg. Chem. 58, 8884-8889 (2019).

46. Sajjadi, M. et al. Palladium nanoparticles stabilized on a novel Schiff base modified Unye bentonite: Highly stable, reusable and efficient nanocatalyst for treating wastewater contaminants and inactivating pathogenic microbes. Sep. Purif. Technol. 237, 116383 (2020).

47. Nasrollahzadeh, M. et al. Pd nanocatalyst stabilized on amine-modified zeolite: Antibacterial and catalytic activities for environmental pollution remediation in aqueous medium. Sep. Purif. Technol. 239, 116542 (2020).

48. Moyo, M., Modise, S. J. \& Pakade, V. E. Palladium nanoparticles dispersed on functionalized macadamia nutshell biomass for formic acid-mediated removal of chromium(VI) from aqueous solution. Sci. Total Environ. 743, 140614 (2020).

49. Khan, S. U., Islam, D. T., Farooqi, I. H., Ayub, S. \& Basheer, F. Hexavalent chromium removal in an electrocoagulation column reactor: Process optimization using CCD, adsorption kinetics and $\mathrm{pH}$ modulated sludge formation. Process Saf. Environ. Prot. 122, 118-130 (2019).

50. Sanchez-Hachair, A. \& Hofmann, A. Hexavalent chromium quantification in solution: Comparing direct UV-visible spectrometry with 1,5-diphenylcarbazide colorimetry. C. R. Chim. 21, 890-896 (2018).

51. Vilardi, G. P-aminophenol catalysed production on supported nano-magnetite particles in fixed-bed reactor: Kinetic modelling and scale-up. Chemosphere 250, 126237 (2020).

52. Owija, N. Y., Kosa, S. A. \& Salam, M. A. Removal of cadmium ions from aqueous solution by zero valent iron nanoparticles: Equilibrium and thermodynamic studies. J. Mol. Liq. 342, 117462 (2021).

53. Tran, H. N., You, S.-J., Hosseini-Bandegharaei, A. \& Chao, H.-P. Mistakes and inconsistencies regarding adsorption of contaminants from aqueous solutions: A critical review. Water Res. 120, 88-116 (2017).

54. Chen, S. et al. Novel lignin-based phenolic nanosphere supported palladium nanoparticles with highly efficient catalytic performance and good reusability. Ind. Crop. Prod. 145, 112164 (2020).

55. Li, S., Liu, L., Zhao, Q., He, C. \& Liu, W. N-doped graphene-supported PdCu nanoalloy as efficient catalyst for reducing $\mathrm{Cr}(\mathrm{VI})$ by formic acid. Phys. Chem. Chem. Phys. 20, 3457-3464 (2018).

56. Tripathi, R. M. \& Chung, S. J. Reclamation of hexavalent chromium using catalytic activity of highly recyclable biogenic $\operatorname{Pd}(0)$ nanoparticles. Sci. Rep. 10, 640 (2020).

57. Yang, C., Meldon, J. H., Lee, B. \& Yi, H. Investigation on the catalytic reduction kinetics of hexavalent chromium by viral-templated palladium nanocatalysts. Catal. Today 233, 108-116 (2014).

58. Celebi, M., Yurderi, M., Bulut, A., Kaya, M. \& Zahmakiran, M. Palladium nanoparticles supported on amine-functionalized SiO2 for the catalytic hexavalent chromium reduction. Appl. Catal. B Environ. 180, 53-64 (2016).

59. Celebi, M., Karakas, K., Ertas, E. I., Kaya, M. \& Zahmakiran, M. Palladium nanoparticles decorated graphene oxide: Active and reusable nanocatalyst for the catalytic reduction of hexavalent chromium(VI). ChemistrySelect 2, 8312-8319 (2017).

60. Petek, A. \& Krajnc, M. The enthalpy and entropy of activation for ethyl acetate saponification. Int. J. Chem. Kinet. 44, 692-698 (2012).

61. Oguntimein, G. B. Biosorption of dye from textile wastewater effluent onto alkali treated dried sunflower seed hull and design of a batch adsorber. J. Environ. Chem. Eng. 3, 2647-2661 (2015).

62. Noh, J.-H. \& Meijboom, R. Dendrimer-templated Pd nanoparticles and Pd nanoparticles synthesized by reverse microemulsions as efficient nanocatalysts for the Heck reaction: A comparative study. J. Colloid Interface Sci. 415, 57-69 (2014).

63. Hong, C.-B., Zhu, D.-J., Ma, D.-D., Wu, X.-T. \& Zhu, Q.-L. An effective amino acid-assisted growth of ultrafine palladium nanocatalysts toward superior synergistic catalysis for hydrogen generation from formic acid. Inorg. Chem. Front. 6, 975-981 (2019).

64. Feng, T. et al. Covalent triazine frameworks supported CoPd nanoparticles for boosting hydrogen generation from formic acid. Appl. Surf. Sci. 469, 431-436 (2019).

65. Zhao, X., Dai, P., Xu, D., Li, Z. \& Guo, Q. Ultrafine palladium nanoparticles anchored on NH2-functionalized reduced graphene oxide as efficient catalyst towards formic acid dehydrogenation. Int. J. Hydrogen Energy 45, 30396-30403 (2020).

66. Akbayrak, S., Tonbul, Y. \& Ozkar, S. Nanoceria supported palladium (0) nanoparticles: Superb catalyst in dehydrogenation of formic acid at room temperature. Appl. Catal. B Environ. 206, 384-392 (2017).

67. Mohagheghian, A., Ayagh, K., Godini, K. \& Shirzad-Siboni, M. Photocatalytic reduction of Cr(VI) from synthetic, real drinking waters and electroplating wastewater by synthesized amino-functionalized $\mathrm{Fe} 3 \mathrm{O} 4-\mathrm{WO} 3$ nanoparticles by visible light. J. Ind. Eng. Chem. 59, 169-183 (2018).

68. Khalifa, E. B., Rzig, B., Chakroun, R., Nouagui, H. \& Hamrouni, B. Application of response surface methodology for chromium removal by adsorption on low-cost biosorbent. Chemom. Intell. Lab. Syst. 189, 18-26 (2019).

69. Wei, L.-L., Gu, R. \& Lee, J.-M. Highly efficient reduction of hexavalent chromium on amino-functionalized palladium nanowires. Appl. Catal. B Environ. 176-177, 325-330 (2015).

70. Yin, Y., Hao, J., Yang, Y., Zhao, J. \& Song, J. Polyethylenimine modified ultrafine palladium nanocrystals on reduced graphene oxide for hexavalent chromium reduction. Appl. Surf. Sci. 560, 149926 (2021).

71. Bashir, M. S. Benign fabrication process of hierarchal porous polyurea microspheres with tunable pores and porosity: Their Pd immobilization and use for hexavalent chromium reduction. Chem. Eng. Res. Des. 175, 102-114 (2021).

72. Liang, M. et al. Reduction of hexavalent chromium using recyclable $\mathrm{Pt} / \mathrm{Pd}$ nanoparticles immobilized on procyanidin-grafted eggshell membrane. Ind. Eng. Chem. Res. 53, 13635-13643 (2014).

73. Li, S. et al. Catalytic reduction of hexavalent chromium by a novel nitrogen-functionalized magnetic ordered mesoporous carbon doped with Pd nanoparticles. Environ. Sci. Pollut. Res. 23, 22027-22036 (2016).

74. Kim, J. D. \& Choi, H. C. Efficient catalytic reduction of hexavalent chromium with Pd-decorated carbon nanotubes. Bull. Korean Chem. Soc. 37, 744-747 (2016).

75. Tian, X., Liu, M., Iqbal, K., Ye, W. \& Chang, Y. Facile synthesis of nitrogen-doped carbon coated Fe3O4/Pd nanoparticles as a high-performance catalyst for $\mathrm{Cr}(\mathrm{VI})$ reduction. J. Alloys Compd. 826, 154059 (2020). 


\section{Acknowledgements}

The financial support provided by the Vaal University of Technology and the National Research Foundation (NRF) of South Africa through grant number TTK160510164648 and bursary to MM is acknowledged.

\section{Author contributions}

M.M.: Conceptualization, Formal analysis, wrote the main manuscript text, Writing-review \& editing, Data curation; Investigation. S.J.M.: Conceptualization, Supervision, review \& editing, Resources. V.E.P.: Conceptualization; review \& editing, Funding acquisition, Supervision, Project administration; Resources.

\section{Competing interests}

The authors declare no competing interests.

\section{Additional information}

Correspondence and requests for materials should be addressed to V.E.P.

Reprints and permissions information is available at www.nature.com/reprints.

Publisher's note Springer Nature remains neutral with regard to jurisdictional claims in published maps and institutional affiliations.

(c) (i) Open Access This article is licensed under a Creative Commons Attribution 4.0 International License, which permits use, sharing, adaptation, distribution and reproduction in any medium or format, as long as you give appropriate credit to the original author(s) and the source, provide a link to the Creative Commons licence, and indicate if changes were made. The images or other third party material in this article are included in the article's Creative Commons licence, unless indicated otherwise in a credit line to the material. If material is not included in the article's Creative Commons licence and your intended use is not permitted by statutory regulation or exceeds the permitted use, you will need to obtain permission directly from the copyright holder. To view a copy of this licence, visit http://creativecommons.org/licenses/by/4.0/.

(C) The Author(s) 2021 